\title{
3 Codificación de la variable lingüística
}

Mediante el empleo de un programa de concordancias (Wordsmith 6.0), se localizaron en el corpus todas las ocurrencias de las estructuras lingüísticas que se detallan más adelante en §4.2, y en las que es posible encontrar la alternancia entre las variantes queístas y preposicionales. A continuación, cada ejemplo se codificó de acuerdo con diversos factores lingüísticos, estilísticos y sociales sobre los que la bibliografía previa ha llamado en algún momento la atención, especialmente en estudios sobre comunidades de habla contemporáneas. Con todo, a estos se añaden otros que, hasta donde llega nuestro conocimiento, no se han utilizado como potencialmente explicativos de la variación.

A continuación, exponemos el modo en que se han configurado cada uno de estos factores y las principales hipótesis de partida que de ello se derivan. Dada su naturaleza diversa, a efectos expositivos dividimos esta exposición en tres apartados. En el primero (§3.1), presentamos las diferentes construcciones sintácticas sobre las que se realizará posteriormente el análisis de regresión. Por su parte, las dos secciones siguientes desarrollan los factores lingüísticos (§3.2) y extralingüísticos (§3.3) que se incluyen en el análisis.

\subsection{Tipos de construcción}

Como vimos, las estructuras queístas pueden agruparse en dos grandes bloques (Gómez Torrego 1999, 2135-2145). Por un lado, hablamos de queísmo conjuntivo para aludir a las construcciones en las que la preposición desaparece en la introducción de subordinadas completivas dependientes de:

a) verbos pronominales (me enteré (de) que);

b) verbos no pronominales (trato (de) que);

c) complementos de adjetivos, ya sea en estructuras atributivas (estoy seguro (de) que), ya en construcciones pasivas con participios (he sido informado (de) que);

d) complementos de sustantivos, a menudo en construcciones semilocutivas con verbos de apoyo (me he dado cuenta (de) que);

e) locuciones conjuntivas (a pesar (de) que) y adverbiales (encima (de) que);

f) algunos casos aislados adicionales (es hora (de) que).

Por su parte, el queísmo pronominal implica la supresión de las preposiciones delante del pronombre de relativo que cuando esta viene exigida por el régimen del antecedente. Aparece en: 
a) estructuras ecuacionales (fue por María (por la) que supe esto);

b) con la función del relativo como complemento indirecto (hay personas (a las) que les cuesta);

c) complemento circunstancial (es la casa (en la) que vivo);

d) complemento del nombre (el denominado «quesuismo»: es la mujer (cuyo) que su marido ganó el premio);

e) construcciones con la misma preposición en el antecedente (en la fábrica (en la) que trabajo hay aire acondicionado).

Para el presente estudio, seleccionamos algunos de los casos más productivos de estos grupos, como los que se ilustran a continuación con fragmentos extraídos del corpus en varios momentos de la historia.

\section{- Complementos de sustantivos}

(1) ... lo mismo a catalina de uuiedo y su marido y q tuue notiçia $q$ uino aqui su hija y nunca la ui ni lo supe esta ya ida p[ar]a el piru q si yo la uiera la regalara en lo q pudiera (Cartas de particulares en Indias del siglo XVI, 1582).

(2) ... temerosos nos hallábamos del suceso nos ha empezado a dar buenas esperanzas de él, pues en cartas de 17 de este mes me escribe don Juan que, teniendo noticia de que se hallaban en San Feliú gran cantidad de embarcaciones cargadas de bastimentos para entrar en la plaza, fue con catorce galeras y mil (Correspondencia de Felipe IV con María Jesús de Ágreda, 1652).

\section{- Complementos de adjetivos}

(3) ... ni otra ninguna consideración humana me pudiera dar atrivimiento para suplicar a vuestra majestad mande rever este negocio si no estuviera persuadido que en ello hago a vuestra majestad el mayor servicio que podré hacer en mi vida y en cosa muy importante a la conciencia, autoridad y reputación de vuestra majestad (Memoria manuscrita, 1574).

(4) ni aquí puedo deçir más de q(ue) suplico a Dios me guarde a V(uestra) P(aternida)d y a n(uest)ro P(adr)e M(aestr)o Antolínez, y q(ue) estoy satisfecha de q(ue) no se a visto ningún papel del s(an)to m(aestr)o Curiel (Epistolario de Ana de Jesús, 1610).

- Complementos de verbos pronominales

(5) En lo que, señores, decís que muchos de los que traen los mantenimientos para los reales se quexan que no ay personas diputadas para registrar los mantenimientos, y que sy las hallan les llevan vn real de carta de seruiçio (Correspondencia de Hernando De Zafra, 1489).

(6) ... y en el entretanto vino fray Luis de Granada, al cual le di la carta de V.M. y la del Legado, y con su bondad y llaneza se admiró de que hubiese en el mundo quien pudiese hacer una maldad tan grande, y que él jamás cayera en ello (Carta del Duque de Alba, en Epistolario de Fray Luis de Granada, 1581). 
- Complementos de verbos no pronominales

(7) ... hemos dejado de hazer especialmente esta jornada confiando que de lo que trabajamos aca, aunque no es tanto quanto devemos, en la salvación de esta gente nuevamente convertida ha de holgar mucho más (Un epistolario del arzobispo de Granada Gaspar de Ávalos, 1532).

(8) ... notificándole la falta que les hago en las curaciones con mi ida. En donde me han obligado a que mande por ti, en el tiempo de un año, bajo fianza de seis mil pesos (Cartas desde América, 1700-1800, 1753).

- Locuciones (conjuntivas, preposicionales, adverbiales)

(9) A los que les faltan los Reales y el oro tratan Hagora de hazer otra Vnión. No sé si se acauarán de Concertar, que en caso que no lo hagan será perdello (Cartas de mercaderes, 1615).

(10) Lo que os ruego es que si se pudiere antes de que yo me muera lo vengáis a ver porque no me lo coma la tierra con este dolor (El hilo que une, 1614).

\section{- Oraciones de relativo}

Por tratarse de las subordinadas relativas que presentan un rendimiento funcional más alto y, por tanto, aquellas que mejor pueden facilitar un análisis variacionista para el que se requiere de muestras suficientemente amplias, en el presente bloque limitamos nuestra atención a un grupo de subordinadas dependientes de sustantivos que encierran contenidos temporales y locativos. Los fragmentos siguientes son dos ejemplos representativos:

(11) ... porque los ministros, quando no ban al Consejo el día que se trata un negocio en que alguno está impedido, no vota, y yo devo hacer lo mismo (Diario de Cristóbal de Crespí, 1657).

(12) ... una posición revolucionarla que sólo puede entorpecer el reconocimiento de nuestra personalidad por parte de los aliados, el día en que éstos comprendan cuál es el único camino que puede llevarles a la victoria (Un catalanófilo de Madrid, 1942).

El factor tipológico ha sido, con diferencia, el más atendido por la bibliografía dialectológica y sociolingüística en las investigaciones basadas en comunidades de habla contemporáneas. Con todo, no todos los grupos mencionados han recibido la misma atención por parte de los estudiosos, siendo los complementos de verbos y, en menor medida, las completivas dependientes de categorías nominales (sobre todo, con verbos soporte) los entornos sintácticos más estudiados. Sin embargo, el interés por el queísmo conjuntivo entre las locuciones ha sido menor, aunque todavía lo ha sido menos el queísmo pronominal (y ello pese a su extraordinaria frecuencia a lo largo de la historia).

Aun con diferencias metodológicas y muestrales considerables entre unos estudios y otros, un repaso de los resultados obtenidos en esas investigaciones 
suele mostrar una clara jerarquía entre las soluciones queístas de cada bloque. En cabeza de estas, aparecen con frecuencia los complementos de verbos pronominales, como sucede en los estudios realizados en Tenerife (1980, 81\%; 1996, 82\%; Almeida 2009a), Santiago de Chile (89\%; San Martín 2016), Caracas (89\%; P. ${ }^{1}$ 79; Bentivoglio/Galué 1998-1999; Galué 2005), Valencia (72\%; .67; Gómez Molina 2013), San Juan de Puerto Rico (80\%; Rivera Mercado 1998) o Braga (82,5\% ; Herdeiro/Barbosa 2015), en este último caso para el portugués $(82,5 \%){ }^{2}$ Incluso en aquellos casos en los que estas proporciones bajan significativamente, los números de este queísmo superan a las del resto. Así, en un estudio sobre el habla de Valencia (Gómez Molina/Gómez Devís 1995), sus autores encuentran cifras del 60\% para este grupo de construcciones queístas, frente a tan solo $28 \%$ entre los verbos no pronominales. Incluso ante un cuestionario de aceptabilidad, que revela considerables dosis de inseguridad lingüística, las respuestas favorables a los verbos pronominales (54\%) superan a las de los verbos no pronominales, aunque ya por bastante menos distancia (45\%). Por su parte, Arjona (1979), en un estudio pionero sobre el fenómeno en Ciudad de México, encontraba proporciones de esta clase de queísmo significativamente menores que las consideradas hasta el momento-y con apenas diferencias entre la norma culta (44\%) y la popular (41\%) - , pero que superaban de nuevo ampliamente las advertidas entre los demás verbos (norma culta: 7\%; norma popular: 22\%).

La recurrencia de estos resultados ha llevado a algunos autores a postular la hipótesis de que el queísmo entre los verbos pronominales habría precedido en el tiempo al de otras categorías. Así, en relación con el queísmo conjuntivo en construcciones verbales, Almeida $(2009,27)$ aventura que: «Es probable que el fenómeno se iniciara en un contexto con verbo pronominal y de ahí se extendiera a los verbos no pronominales». Sea o no así-y ocasión tendremos de comprobarlo en esta investigación pancrónica-, lo cierto es que los estudios contemporáneos sitúan sistemáticamente por detrás a las demás categorías sintácticas. Entre estas, figura el resto de complementos verbales, como ya hemos visto en el párrafo anterior. A las ya mencionadas en este, cabe añadir los datos de Santiago de Chile, donde San Martín (2016) advierte proporciones que tan solo alcanzan el 14\% entre los verbos no pronominales, frente al $87 \%$ entre los pronominales. Las diferencias son también muy elevadas en Caracas (22\%; .26 vs. 89\%; .79;

\footnotetext{
1 Como explicamos más arriba (ver supra §3.2), esta abreviatura da cuenta del peso explicativo de un factor determinado en aquellos estudios que han utilizado la regresión logística para la validación de los resultados. Sin embargo, a partir de aquí, seguimos las convenciones habituales en los estudios variacionistas y sustituimos esa P. por un simple punto, seguido del valor alcanzado por ese estadístico.
}

2 Con todo, en este trabajo todos los verbos están agrupados en una misma categoría. 
Bentivoglio/Galué 1998-1999), y, aunque menos pronunciadas, se aprecian también en Tenerife (muestra de 1980, 40\% vs. 81\%; muestra de 1996, 54\% vs. 82\%; Almeida 2009a) y Valencia (35\%; .38 vs. 72\%; .67; Gómez Molina 2013). Los ejemplos en los que la distancia entre ambas clases de verbos se atenúa son más escasos, aunque tampoco faltan en la bibliografía. Así, en el nivel popular de San Juan de Puerto Rico, Rivera Mercado (1998) detecta proporciones muy elevadas tanto en los verbos no pronominales (71\%) como en los pronominales (80\%).

Los complementos de categorías nominales suelen figurar en la cola de las realizaciones queístas, especialmente en las construcciones que no dependen de un verbo soporte (ver infra §3.2.10). Así, en Tenerife, Almeida (2009a) comprueba la existencia de índices considerablemente mayores de la variante cero en colocaciones como darse cuenta, tener duda y similares (1980, 39\%; 1996, 47\%) que cuando los sustantivos aparecen en entornos menos constreñidos sintáctica y semánticamente (1980, 8\%; 1996, 13\%). Y, aunque con diferencias menos acusadas, jerarquías similares se han reseñado en otras comunidades, como Valencia (56\% vs. 30\%; Gómez Molina/Gómez Devís 1995) 3 o Ciudad de México (norma popular: $28 \%$ vs. $18 \%$; norma culta: $21 \%$ vs. 5\%; Arjona 1979).

Menos frecuentes son, sin embargo, los estudios que han atendido a la distinción entre el carácter sustantivo o adjetivo del elemento nuclear. Los que sí lo han hecho muestran disparidad de resultados, incluso en una misma comunidad lingüística. Así, en el nivel popular de Ciudad de México, Arjona (1979) encuentra ejemplos equilibrados de queísmo en ambas categorías (en torno al $30 \%$ ), mientras que en la norma culta no hay ningún caso entre los complementos de adjetivos. Por su parte, San Martín (2016) muestra proporciones elevadas, y cercanas entre sí, en ambas categorías en Santiago de Chile (sustantivos: 56\% vs. adjetivos: 50\%). Como contrapartida, en un estudio sobre discursos presidenciales en Chile, Echeverría (2016) advierte cifras significativamente mayores de queísmo con adjetivos (57\%) que con sustantivos (35\%). Lo mismo sucede en Caracas, donde Bentivoglio/Galué (1998-1999) señalan magnitudes mucho más prominentes de queísmo entre los adjetivos (56\%; .59)-limitadas, en este caso, a las estructuras atributivas-que entre los sustantivos (16\%; .13). Y la misma jerarquía encontramos en San Juan de Puerto Rico, donde las proporciones de la variante cero entre los adjetivos son muy elevadas (73\%), y netamente superiores a las recogidas entre los sustantivos (54\%). Con todo, no faltan los ejemplos de lo contrario. Entre estos se encuentra la ciudad de Valencia, con una leve ventaja significativa estadísticamente (.45 vs. .36) (Gómez Molina 2013). En todo caso, más

3 Con todo, en un estudio más reciente de Gómez Molina (2013) acerca de esta misma comunidad urbana, el autor advierte cifras mucho más próximas entre ambos entornos nominales (38\% vs. $35 \%$ ). 
claras son aún estas diferencias en el portugués de Braga, donde Herdeiro/Barbosa (2015) advierten entre los sustantivos cifras muy elevadas de la variante vernácula (86\%), que superan incluso las halladas entre los complementos verbales (82,5\%), y a distancia ambas de los complementos adjetivales (67\%).

Entre los pocos estudios que han puesto el foco en la categoría de las locuciones los resultados son también dispares. En ocasiones, el queísmo en estas construcciones ocupa posiciones rezagadas con respecto a otras, como muestran los datos de Tenerife (1980) (14\%; Almeida 2009a) o Ciudad de México, especialmente en la norma culta (0\%; norma popular: 18\%; Arjona 1979). Por su parte, Gómez Molina (2013) incluye estas construcciones junto a otras periféricas en una misma categoría (Otros), en la que detecta muy pocos ejemplos de queísmo en la ciudad de Valencia (6\%) y el peso explicativo más bajo de todos los considerados en el estudio (.26). Aun así, la diversidad dialectal en el extenso dominio hispánico se aprecia también aquí, con comunidades de habla en las que la variante cero muestra proporciones mucho más altas. Así ocurre en Caracas (64\%), con cifras que tan solo tienen por delante las halladas entre los verbos pronominales, y a considerable distancia de las demás construcciones (Bentivoglio/Galué 1998-1999). Singularmente elevados son también los números de esta categoría en Santiago de Chile, tanto en el conjunto de la comunidad (56\%; San Martín 2016), como en el análisis específico de la norma culta (79\%; Rabanales 2005), aunque esta última cifra haya que tomarla con precaución debido a las limitaciones muestrales $(n=11)$.

Estos mismos problemas muestrales dificultan la valoración del queísmo pronominal en los escasos estudios en que se ha considerado cuantitativamente, pese a tratarse de un fenómeno que, al igual que el conjuntivo, aparece ya documentado desde los mismos orígenes del español (RAE 1931, 315-316; Keniston 1937, 208 y ss.; RAE 1973, 529; Gutiérrez Araus 1985, 17-18; Lope Blanch 1989, 83-84). Entre estos figuran algunos trabajos sobre el corpus de la norma culta en ciudades como Lima, donde McLauchlan (1982) advierte proporciones discretas de queísmo (33\%; $n=16$ ), superadas con creces tanto por los verbos pronominales y no pronominales como por las locuciones. El mismo dibujo mantienen las cifras en la norma culta de Santiago de Chile (Rabanales 2005), aunque los porcentajes para el queísmo pronominal sean esta vez mayores, y mejor su representación en el corpus (50\%; $n=52$ ). Estos números mejoran incluso en el estudio de esta comunidad de habla llevado a cabo recientemente por San Martín (2016) a partir del corpus PRESEEA (67\%), en uno de los escasos trabajos sociolingüísticos sobre el queísmo que incluye esta categoría en el objeto de estudio. Por otro lado, estos índices sitúan a este grupo sintáctico como uno de los principales nichos de queísmo en la capital chilena. Aunque sin aportar cifras concretas, Gutiérrez Araus $(1985,36)$ señala también que el queísmo en las relativas es un fenómeno muy frecuente en Puerto Rico, lo que «es una prueba más del alto grado de gramaticalización en que se halla 
la forma que [...] constituyendo un primer momento en el camino de convertirse en simple conjunción». ${ }^{4}$ Ya en España, los estudios de Carbonero (1985) y Lope Blanch (1989) sobre el habla culta de Sevilla y Madrid, respectivamente, así como los de Cortés Rodríguez (1990) sobre una muestra de hablantes leoneses, y de Herrera Santana (1997) en la comunidad de Santa Cruz $^{5}$ de Tenerife revelan también proporciones elevadas.

Del repaso de la bibliografía realizado en los párrafos anteriores se deduce que las magnitudes del fenómeno difieren notablemente entre unas construcciones sintácticas y otras en todo el dominio hispanohablante. Además, un examen detenido de esas categorías revela también la existencia de algunas diferencias notables en el interior de cada grupo, con variaciones muy importantes entre algunas estructuras específicas. Así, por ejemplo, en varios de los estudios reseñados se menciona la extraordinaria extensión del queísmo con algunos verbos pronominales concretos, como acordarse o alegrarse (Arjona 1979; Carbonero 1991; Del Valle 1996-1997; Rabanales 2005; San Martín 2016), cuyas cifras se sitúan muy por encima de las tendencias centrales halladas en los demás verbos del mismo tipo. Este hecho, fundamental para interpretar cabalmente la variación, no se ha tenido en cuenta apenas en las investigaciones llevadas a cabo hasta la fecha, lo que dificulta evaluar con precisión el alcance que el fenómeno adquiere en cada caso.

En el presente estudio queremos salvar este importante escollo dando entrada al primero de los factores condicionantes que se detallan a continuación.

\subsection{Factores lingüísticos}

\subsubsection{Estructuras lingüísticas}

Para comprobar el grado de homogeneidad del queísmo en las construcciones expuestas en el apartado anterior, y evitar así conclusiones precipitadas, en el análisis de regresión incorporamos como un predictor aleatorio (ver infra §4.2) cada una de las estructuras lingüísticas consideradas en su interior. Como criterio general, y para facilitar el estudio pancrónico, en esta investigación limitamos la nómina a aquellas construcciones que se han revelado más productivas dentro

\footnotetext{
4 A similares conclusiones llegan algunos gramáticos (Alcina/Blecua 1991, 1033-1035; Hernández 1996, 264-265), no faltando, incluso, quienes interpretan este que como un elemento en nada diferente al que conjuntivo (Trujillo 1990, 24).

5 Carbonero (1985, 73-76) recuerda al respecto que, frente a los relativos el cual, el que o quien, que aparecen con asiduidad junto a la preposición, con que sucede todo lo contrario.
} 
de cada uno de los bloques mencionados a lo largo de la historia del español. Ello facilitará su seguimiento en el eje diacrónico, eludiendo así, en la medida de lo posible, desequilibrios muestrales que pudieran poner en peligro nuestro objetivo. Así, de la muestra final hemos desechado algunos esquemas sintácticos cuya representatividad ha podido ser alta en algunos momentos, pero insignificante o nula en otros. Por ejemplo, el verbo pronominal holgarse aparece con considerable frecuencia en los textos epistolares de los Siglos de Oro, pero su presencia decae ya notablemente en el XVIII (apenas dos ocurrencias) hasta desaparecer en las centurias posteriores. Del mismo modo, sustantivos como sentido o adjetivos como consciente son en la actualidad el núcleo del que dependen numerosas completivas (en el sentido (de) que, soy consciente (de) que...). Sin embargo, su aparición en los textos de inmediatez examinados en estas páginas se ha demostrado irrelevante.

Así las cosas, las construcciones a las que se limita el análisis comparativo del queísmo son las siguientes: ${ }^{6}$

Complementos de adjetivos: admirado, advertido, asegurado, avisado, confiado, contento, convencido, culpable, deseoso, enterado, informado, persuadido, quejoso, satisfecho, seguro.

Complementos de sustantivos: acuerdo, advertencia, amenaza, aviso, causa, conciencia, confianza, convencimiento, cuenta, cuidado, culpa, deseo, duda, esperanza, fe, gana(s), hecho, hora, idea, información, miedo, motivo, necesidad, noticia, ocasión, opinión, orden, palabra, peligro, posibilidad, queja, razón, riesgo, ruego, rumor, seguridad, sentido, suerte, temor.

Complementos de verbos: advertir, aguardar, amenazar, avisar, confiar, convencer, cuidar, depender, dudar, hablar, informar, insistir, obligar, persuadir, soñar, tratar, acordarse, admirarse, alegrarse, asegurarse, contentarse, convencerse, encontrarse, enterarse, olvidarse, persuadirse, quejarse.

\footnotetext{
6 Por las razones aludidas, en cada una de las categorías se han descartado otras locuciones inicialmente buscadas en el corpus, como las siguientes: a) complementos de adjetivos: consciente, feliz, alegre, harto, orgulloso, pendiente, preocupado; b) complementos de sustantivos: impresión, conclusión, idea, posibilidad, sensación, problema, sorpresa, sentido, medida, tiempo; c) complementos de verbos: percatarse, arrepentirse, preocuparse, ocuparse, fijarse, referirse, acostumbrarse, encontrarse, depender, coincidir, empezar, holgarse, disuadir, animar, persistir, esforzarse, negarse; d) locuciones: a cambio (de) que, encima (de) que, a favor (de) que.
} 
Locuciones: a causa (de) que, a fin (de) que, a menos (de) que, a pesar (de) que, a sabiendas (de) que, además (de) que, antes (de) que, aparte (de) que, (a/con) (la) condición (de) que, ${ }^{7}$ con tal (de) que, después (de) que, en (el) caso (de) que, en vista (de) que, hasta el punto (de) que, respecto (a/de) que.

Complementos de sustantivos en oraciones relativas: año, día, época, hora, instante, lugar, mañana, mes, momento, noche, ocasión, sitio, situación, tiempo, vez.

A continuación, se describen algunos predictores que hemos utilizado en el análisis de la variable lingüística en todas las construcciones examinadas, al tiempo que reservamos para más adelante otros que únicamente se han tomado en consideración en ciertos tipos, dadas sus características particulares.

\subsubsection{Modo de la subordinada}

Un factor que consideramos en todas las construcciones sintácticas es el modo verbal de la cláusula subordinada. El modo es una categoría que revela las actitudes y el punto de vista que el hablante puede adoptar con respecto a los enunciados que expresa, pero también es un elemento gramatical íntimamente asociado a las relaciones sintácticas que mantienen las cláusulas entre sí. De esta forma, la selección del modo verbal conlleva implicaciones semánticas, pragmáticas y sintácticas que pueden estar correlacionadas con el fenómeno que nos ocupa, aunque con consecuencias no siempre fácilmente predecibles.

Así, es sabido que el modo indicativo concibe las acciones y procesos denotados por el verbo como reales, mientras que el subjuntivo las presenta como virtuales o posibles, con matices de duda, temor, deseo, etc. Como advierte King (1992), el indicativo expresa mayor objetividad y asertividad, mientras que el subjuntivo manifiesta las nociones contrarias. En este sentido, cabría suponer, como hace Martínez Sequeira (2000) en relación con el dequeísmo, y a partir de las ideas esbozadas previamente por otros autores (García 1986; Lavandera 1990; Schwenter 1999), que el modo subjuntivo promoverá en mayor medida el uso icónico de la preposición, como un reflejo de las actitudes más distantes del

7 Según Herrero Ruiz de Loizaga (2014, 2818), en el español moderno, ambas posibilidades se diferencian formalmente: con la condición (de) que para el complemento circunstancial de modo, y a condición (de) que para la locución conjuntiva condicional. Dado que en este trabajo nos interesa sobre todo la alternancia entre los usos prepositivos y elididos del enlace, y no tanto el valor sintáctico-semántico de la locución, incluimos en el mismo grupo las ocurrencias de ambas. 
hablante con respecto al contenido de sus enunciados. Por el contrario, la mayor objetividad del indicativo debería favorecer las elisiones.

Ahora bien, al mismo tiempo se ha subrayado que el modo subjuntivo se halla estrechamente asociado al propio concepto de subordinación (Raible 1983, 289; Serradilla 1997, 214-215). De hecho, en la historia del español, no han faltado episodios de elisión del nexo que en algunos contextos sintácticos subordinados, como las completivas, los cuales se han puesto en relación-entre otros motivos-con este hecho (Pountain 2015; Blas Arroyo/Porcar 2018). Si ello ha ocurrido con que, con más razón podría suceder con un segundo elemento subordinante como la preposición, que, en este sentido, podría interpretarse todavía como más superfluo. Desde este punto de vista, pues, la hipótesis de partida sería inversa a la anterior: los casos de queísmo serán más frecuentes cuando la subordinada selecciona el modo subjuntivo que cuando se combina con el indicativo.

Los fragmentos que se incluyen a continuación ejemplifican las dos variantes en liza, en varias de las construcciones examinadas y en diferentes momentos de la historia.

\section{Indicativo:}

(13) Y deseando de tener más aparejo para servir, me atrebo a suplicarle me aga todo favor para con sus magestades y pues a V.S tengo por pastor, yo tengo confiança en nuestro Señor que, mediante V.S. illustríssima, mis servicios serán remunerados (Licenciado Artaga, en La mort del duc de Calàbria, 1556).

(14) Ahora que, como te he dicho otras veces, empleo muy bien el tiempo estudiando, y apenas me acuerdo que estoy preso si no es por lo mucho que os echo de menos (Miguel Hernández. Cartas a Josefina, 1940).

(15) ... confío en que no ha de faltarnos el auxilio Divino para nuestros planes y, siendo así, ¿qué duda cabe que llegaremos al término? (Pilar Velasco, en Epistolario del padre Poveda, 1914).

(16) Doy quenta a Vuestra Magestad dello por tocar en materia grave y aviso juntamente de que apuntaron a decir que si el comisario de los frayles por la omnimoda entretanto que va persona por el Santo Oficio hiciese autos algunos en causas de la fee le castigarian... (Correspondence of Gaspar de Zúñiga y Acevedo, 1598).

Subjuntivo:

(17) Y, así, tomé resolución de ynbiárselos a Vm originales con riesgo de que se pierdan; allá ban con poder para Vm de uno de mis albaçeas, que es Francisco de Uçena, el qual no se llama sino Francisco de Luçena... (fray Juan de la Cueva, en Correspondencia privada de Diego de la Cueva y su hermano Juan, 1620).

(18) Aguardé que viniera, y aún no se había ido la gente de la puerta cuando llegó y me dijo «Suba acá, señor alférez». (Alonso de Contreras, Discurso de mi vida, 1630). 
(19) El correo marítimo de esa no ha llegado y también sale hoy, por el cual te pondré cuatro letras para que no haya ocasión que te encuentres sin carta mía (Cartas desde América, 1700-1800, 1791).

(20) Todos tenemos muy grande deseo de ver a Vmd en esta tierra y nos alegramos mucho de que Vm aya cantado misa, Dios nuestro señor le deje goçar el estado largos años con salud, vida y contento (Correspondencia privada de Diego de la Cueva y su hermano Juan, 1634).

Pese a la relevancia hipotética de este predictor, sorprende el limitado eco que ha tenido en la investigación sobre el queísmo (no así en relación con el dequeísmo), siendo escasos los estudios que lo han tomado en consideración. Entre estos, figura el trabajo de Gómez Molina (2013) sobre la ciudad de Valencia, en cuyos datos el factor no es seleccionado como significativo. Por su parte, Pountain (2014, 12), en una revisión histórica a partir del Corpus del español (Davies 2002) de algunos casos particulares del fenómeno, como las construcciones con el verbo insistir, muestra también que las cifras de la variante queísta con uno y otro modo son muy similares. En el presente estudio, comprobaremos si estas mismas conclusiones se pueden trasladar a las distintas estructuras analizadas.

\subsubsection{Grado de adyacencia y distancia}

Con estos dos predictores pretendemos medir la potencial influencia ejercida por la distancia entre el elemento nuclear y el nexo que, ya se trate de una conjunción, ya de un pronombre relativo. El primero (grado de adyacencia) es un factor categórico mediante el que nos enfrentamos únicamente ante dos posibilidades. Por un lado, se encuentran los casos, mayoritarios en el discurso, en los que la cabeza de la construcción aparece adjunta al nexo subordinante, ya sea de manera inmediata, como en (21) y (22), ya separada por medio de la preposición, como en (23). Frente a esos, los ejemplificados en (24) a (26) suponen la injerencia de otras palabras o sintagmas entre las dos unidades mencionadas.

\section{Adyacentes:}

(21) ... paresçiole poquedad al birrey y cobardia y no quiso porque le auisaron que ya benia el tirano por añaquito vna legua de alli saliole a rreçeuir y a la asomada de añaquito que todos se vieron vnos a otros rrepres (La conquista del Perú. Escritos y crónica de Alonso Borregán, 1586).

(22) Creo que estarían ahí muy bien las reliquias, que así me lo parecieron a mí una vez que las vi. Y no era el día que allí estuvisteis de San Víctor, sino de San Mauricio y sus compañeros (Cartas de Felipe II a sus hijas, 1582). 
(23) Mi muy querida Elvira: Llegó tu carta ayer a mi poder en hora y ocasión en que ya no podía contestarla en el día. Hoy tengo que ir a Ferrol. Quiero echar ésta... (Una pasión imposible. Cartas de amor de Felipe Bello Piñeiro, 1936).

No adyacentes:

(24) Confieso a Vm. que andava buscando cómo huir de estos reqüerdos, persuadido, aunque engañado, de que con ellos iva cobrando fuerzas mi dolor (Epistolario de Juan Basilio de Castellví y Coloma, Conde de Cervellón, 1737).

(25) Polosow jamás quiso consentir en este plan, bajo diferentes pretextos especiosos; pero el que había en realidad era el que quería persuadirme por todos medios que yo entrase en el servicio de Rusia, a lo que siempre resistí pretextando el no poder comprender el idioma (Memorias soldados españoles, 1813).

(26) ... o que han menguado y crecido los introitos desde el año de 1612, que se hizo la consignación y se me envió bilanzo, hasta el año de 1616, que se hizo el último que trujo el conde de Lemos; y del crecimiento de los éxitos del uno al otro (Epistolario de Francisco de Quevedo, 1618).

Alternativamente, en otro análisis medimos de manera más precisa la distancia en número de palabras entre el núcleo y el nexo que. En este caso, el predictor adquiere la condición de continuo, y no fijo o categórico, como en el anterior (para la diferencia entre ambos tipos de predictores, ver infra §4). Lógicamente, todos los contextos considerados adyacentes en el análisis anterior cuentan con un valor nulo en este reanálisis, mientras que ejemplos como los de (24) a (26), adquieren los índices 2, 3 y 2, respectivamente. En el conjunto de la muestra, las distancias encontradas oscilan entre 0 y 13 palabras.

Al igual que sucede con el modo verbal de la subordinada, las hipótesis iniciales acerca de la potencial influencia de este factor en la historia del queísmo pueden ser diversas. Por un lado, cabe prever que el alejamiento entre el elemento regente y el enlace propicie las elisiones de la preposición en mayor medida que la adyacencia, ya que, en tales casos, el hablante puede perder el control sobre la estructura sintáctica que exige la preposición. Sin embargo, de la misma manera que veíamos a propósito del subjuntivo, la adyacencia puede interpretarse también como un índice suficiente de la subordinación. Así, en un estudio sobre la elisión de que en subordinadas completivas dependientes de un predicado doxástico en los Siglos de Oro, tuvimos ocasión de comprobar cómo esa posibilidad era claramente favorecida en los contextos adyacentes, mientras que los no adyacentes actuaban en sentido contrario (Blas Arroyo/Porcar 2018). En el presente estudio, ponemos también a prueba este condicionante, y planteamos la hipótesis de que la adyacencia desaliente la duplicación de nexos, y de que, por el contrario, cuanto más alejados se encuentren el núcleo de la construcción y que, mayor será la probabilidad de encontrar las variantes preposicionales. 
Algunos estudios que han tomado en consideración este factor sintagmático han confirmado en lo esencial esta hipótesis. Así, en su investigación sobre el portugués brasileño, Mollica (1991) advierte diferencias significativas entre los contextos adyacentes $(72 \%$; .64) y no adyacentes $(53 \%$; .36) en el sentido reseñado. Y aunque de menor entidad (.52 vs. .47), la misma dirección explicativa se advierte en el estudio de Schwenter (1999) sobre muestras orales (Madrid) y escritas (Argentina y Chile) del español actual. Por su parte, Almeida (2009a) menciona diferencias frecuenciales destacadas en el español de Tenerife (1996) (70\% vs. 40\%). Sin embargo, Bentivoglio/Galué (1998-1999) no señalan distancias significativas relacionadas con este factor en el habla de Caracas.

\subsubsection{Frecuencia}

Hasta donde llega nuestro conocimiento, este predictor, que se ha demostrado sumamente relevante en la explicación de numerosos procesos de cambio lingüístico, no se ha tomado en consideración en el estudio del queísmo. A partir de una concepción del cambio basada en el uso lingüístico y en principios cognitivos como la persistencia (entrenchment) (Croft 2000; Schmid 2012), se ha comprobado que las estructuras y contextos más frecuentes tienden a favorecer el uso de las variantes más antiguas, dado su mayor afianzamiento cognitivo: «the more a form is used, the more its representation is strengthened, making it easier to access the next time» (Bybee/Thompson 2000, 380). Este efecto "conservador» de las unidades de frecuencia alta se ha demostrado no solo en el nivel léxico (Bybee 1985; 2006; Langacker 1987), sino también en el estudio de diversos fenómenos sintácticos (Givón 1979; Croft 2000; Bybee/Hopper 2001; Blas Arroyo/ Schulte 2017). Por el contrario, las unidades menos frecuentes suelen actuar como puerta de entrada para las formas alternativas.

Concebido en el análisis de regresión como un predictor continuo, que se configura a partir de las frecuencias de aparición de las diferentes expresiones en el corpus, la hipótesis que formulamos es, pues, que cuanto mayor sea la recurrencia de estas, mayores serán también los índices de la variante más tradicional, que, como hemos visto, es, en este caso, la variante queísta. Por el contrario, las construcciones más ocasionales dentro de cada bloque actuarán como un vector para las inserciones preposicionales. De cumplirse esta hipótesis, cláusulas de relativo construidas a partir de sustantivos como día $(n=919)$, o subordinadas dependientes de locuciones como antes de que $(n=749)$, extraordinariamente bien representadas en el corpus, y ejemplificadas a continuación en (27) a (30), mostrarán más resistencia a abandonar los usos queístas que otras construcciones, mucho menos frecuentes dentro de sus bloques respectivos, como mañana 
( $n=50)$ o hasta el punto (de) que ( $n=26)$, ambas ilustradas en (31) a (34). Con todo, este factor puede afectar a las unidades de diferente manera en distintos periodos, en función del grado de recursividad que muestren en cada etapa.

\section{Frecuentes:}

(27) ... aquí lo más corriente es no saber ni en el día que vives, menos mal que tuve una feliz inspiración y me supongo, recibirías un telegrama felicitándote (Félix Solís, en Madrina de guerra, 1941).

(28) ... dieron el mejor cargo de la tierra, que es ser juez de residencia y alcalde mayor de la çibdat de la Veracruz, puerto de la Nueva Spaña, porque antes que el Audiencia Real viniese le queria mucho Ñuño de Guzman, porque desdesta çibdat le proveya de cosas que havia menester (Documentos lingüísticos de la Nueva España, 1529).

(29) Dignaros recibir este tributo de mi corazón para el día en que, saliendo de la onda Febo, nuevamente emprenda la vuelta al mundo; y esa será para mi la época de felicidad (Juan Lanes, en Epistolario de Pedro Rodríguez Campomanes, 1784).

(30) Creo que todavía, si quieres y desechas la desidia, puedes escribirme a esta, en la seguridad de que llegará la carta a mis manos, antes de que me vaya yo para Europa. (Cartas de Juan Valera a sus hijos, 1886).

\section{Menos frecuentes:}

(31) Llegamos a vista de la tierra la noche antes que hiciéramos esta empresa y caminamos muy poco a poco hasta la mañana, que estuvimos muy cerca (Alonso de Contreras. Discurso de mi vida, 1630).

(32) La prueba está, dicen los jerarcas, en que para Serra y Manolo se obtuvieron los permisos, hasta el punto que por falta de interés de ellos, o de decisión, o de pretensión de viajar en aviones o con muchas comodidades, o qué sé yo, incluso les pasó el tiempo y les caducó el visado (Bartolomé Costa, en Correspondencia de Eugenio Granell con sus camaradas del POUM, 1945).

(33) ... se sirva de no tenerme un hora así, porque estoy debiendo más de 1800 reales, sin una mohatra que hice esta mañana de 400, en que perdí 90, y lo que peor es, que mis acreedores me dieron de término hasta fin de febrero (Góngora. Epistolario completo, 1621).

(34) Me dicen estos hombres que el acuerdo del Gobierno es inaceptable, hasta el punto de que no pueden presentárselo a sus compañeros como base de discusión. Han convocado un Congreso extraordinario para el primero de diciembre (Diarios completos de Azaña, 1931).

\subsubsection{Priming}

Con este factor cognitivo deseamos conocer la hipotética incidencia en la variable lingüística del material utilizado en el contexto anterior (Pereira-Scherre/ Naro 1992; Rosemeyer/Schwenter 2019). En su estudio sobre el fenómeno del dequeísmo en el portugués brasileño, Mollica (1991) comprobó una diferencia significativa relacionada con este predictor. Así, cuando dos o más ocurrencias 
de de aparecían en la oración regente previa-ya se tratara de una preposición, ya de una sílaba en el interior de una palabra-, las probabilidades de encontrar la misma preposición aumentaban (35\%; .61). Por el contrario, cuando estas ocurrencias se reducían a cero o a una sola unidad, esas probabilidades disminuían considerablemente $(8 \%$; .39). En palabras de la propia autora: «... that presence of $d e$ leads to more presence of $d e$, whereas absence leads to more absence» (Mollica 1991, 267). Este paralelismo (parallel effect), sin embargo, no se advertía en los casos de queísmo, cuyas cifras en ambos contextos eran singularmente parecidas ( $72 \%$ vs. $71 \%$ ), un resultado que debilitaba la hipótesis sobre el priming.

A partir del estudio de Mollica (1991), otros autores han puesto a prueba este factor en el estudio del español. Por ejemplo, en su análisis sobre el dequeísmo en un corpus oral madrileño, Schwenter (1999) señala que, de los 32 ejemplos encontrados, 12 (32\%) aparecen precedidos por la preposición de, una cifra ligeramente superior a la media obtenida por la variante en el conjunto de la muestra (27\%), pero que la regresión no avala como significativa. Por su parte, Almeida (2009a) llama la atención sobre diferencias frecuenciales significativas en el dequeísmo de Tenerife, y en la misma dirección que en el estudio de Mollica (9,9\% vs. 1,3\%). Por el contrario, en los casos de queísmo, las proporciones se invierten. De este modo, cuando en el entorno previo aparece /de/, las inserciones de la preposición disminuyen $(35,7 \%)$ respecto al contexto opuesto $(51,4 \%)$. Y aunque el autor señala que estas diferencias no resultan significativas de acuerdo con la regresión, parecen apuntar a un efecto disimilatorio, esto es, contrario al priming. Es el mismo que se advierte en el estudio de Bentivoglio/Galué (1998-1999) sobre el habla de Caracas, donde la presencia de un elemento similar a / de/, favorece esta vez de manera mucho más clara (y significativa estadísticamente) la ausencia de la preposición (78\%; .67). Especialmente llamativos son, a este respecto, los resultados cuando ese elemento es la propia preposición de, que representa el contexto menos favorable de todos para las inserciones.

Para la configuración del predictor en nuestro estudio atendemos únicamente a la presencia de la misma preposición en el enunciado anterior, ya se trate de la partícula de, ya de otras, como $a$, con o en, esta última, por ejemplo, mayoritaria en el queísmo pronominal. Por otro lado, para calibrar de manera más objetiva este eventual efecto establecemos una distancia límite: las diez palabras previas al núcleo de la construcción. Nuestra interpretación es, pues, mucho más restrictiva que la de aquellos autores que apuestan por el efecto positivo de este priming en contextos mucho más extensos (Pickering/Ferreira 2008, 447). A nuestro modo de ver, sin embargo, la influencia asimilatoria (o disimilatoria) de ciertos elementos tan solo queda suficientemente garantizada cuando estos se hallan próximos, y se debilita considerablemente conforme se alejan. Y aunque el 
límite establecido podría parecer, ciertamente, arbitrario, tiene como contrapartida la virtud de su objetividad.

Por otro lado, en la interpretación del priming consideramos también una segunda posibilidad (priming 2): la presencia de que en ese contexto previo. En este caso, no atendemos al estatus gramatical del nexo, que puede funcionar como una conjunción o como un pronombre de relativo. El motivo es el mismo que hemos esbozado arriba: antes que un paralelismo gramatical (que llevaría a la potencial influencia tan solo en los casos de identidad categorial: conjunción-conjunción, relativo-relativo), nuestra interpretación de este condicionante es de naturaleza básicamente psicolingüística.

Los ejemplos que aparecen a continuación ilustran los dos contextos que resultan en cada caso, con fragmentos representativos de diferentes momentos en la historia del español.

\section{Priming 1}

Presencia de la misma preposición entre las diez palabras previas al núcleo de la construcción:

(35) ... pues por mucho que haya esperado este santo varón, estoy convencido de que desistiria inmediatamente de su bíblico papel en el caso que le ofreciesen el de hacerse pasar por uno esperando un visado (Correspondencia de Eugenio Granell con sus camaradas del POUM, 1945).

(36) Vista la dificultad de poder vencer el Salto, y riesgo de que se rompiessen las Canoas, si se intentaba superarlo, determinamos volvernos desde este parage, y poner en el un marco... (Diario de la frontera hispano-lusa, 1752).

Otros:

(37) ... el qual me abia abisado miguel de solorzano me ynbiaria en estas naos que agora binyeren y para ello le auia dado orden que gastase çien escudos y no fue dios serbido que llegase aca (Cartas de particulares en Indias del siglo XVI, 1582).

(38) ... pero hasta que pasen dos o tres días más no los pienso entregar a Julia, pues todavía hay la esperanza de que pudiese aparecer por algún lado. No te olvides de escribir a Julia (Asturias que perdimos, 1916).

Al igual que hemos visto en otros estudios sobre el español contemporáneo, la hipótesis de partida es que, lejos de favorecer las inserciones, la presencia de la preposición funcionará como un elemento disimilatorio, y, por consiguiente, alentará las soluciones queístas.

\section{Priming 2}

Presencia de que en el contexto previo, con el mismo límite que en el caso anterior. 
(39) ... que a sido mi cuchillo y destruyzion y pliviera a dios por su pasion que el dia que yo lenbie a llamar que aquel dia tubiera yo una calentura de cuatro días... (Cartas de particulares en Indias del siglo XVI, 1571).

(40) No te franqueo esta, ni preciso franquear ninguna que creo esa es la causa de que se pierdan las que te mando. Señora Doña Teresa Ojeda. Lima y septiembre 13 de 1812 (Historias de América: La emigración española en tinta y papel, 1812).

Otros:

(41) En fin, salvo imposibles sutilezas, no cabe duda que nos reuniremos aquí. Es una casa grande, muy bonita, con parque y un río allá abajo, donde hallarás todo el sosiego que necesitas (Rafael Dieste. Epistolario amoroso, 1939).

(42) La abrazo con todo mi corazón y la considero así desde hoy, y mi deseo y esperanza de que seamos siempre dos buenas hermanas y que reine el afecto, la nobleza, la generosidad y la comprensión y unión entre ella y todos nosotros (Epistolario de Pilar de Zubiaurre, 1942).

La falta de estudios con este predictor dificulta ahora la formulación de hipótesis. Por un lado, podría esperarse que la aparición en el entorno inmediato de que favoreciera el uso de una estructura queísta a continuación, confirmando esta vez sí la influencia del priming. Sin embargo, no es descartable tampoco la posibilidad contraria, esto es, que un efecto disimilatorio aliente las variantes preposicionales.

\subsubsection{Polaridad}

Explicativo en diversos hechos de variación y gramaticalización (Givón 1979; Poplack/Dion 2009; Torres-Cacoullos/Walker 2009; Tagliamonte/Durham/Smith 2014), en esta investigación deseamos valorar las hipótesis acerca del influjo-a menudo conservador-de la polaridad negativa en los procesos de cambio lingüístico. Y aunque el predictor no se ha considerado en estudios previos sobre el queísmo, en el presente comprobaremos si esa polaridad ha podido favorecer las variantes queístas en algún momento de la historia del español, en oposición a las oraciones afirmativas, mayoritarias en el corpus.

\section{Afirmativa:}

(43) ... en este dicho valle nos dieron noticia que dos jornadas de alli estaban cinco pueblos y un descubrimiento de minas; no se fue a ver por no aber llebado el rrecado nessesario (Relación de Hernán Gallegos, 1581).

(44) Suplico a V.S. que por me hazer special mercet en el tiempo que su majestat haia de proveher deste offiçio, se acuerde deste servidor de su majestad (Miquel Beneyto, en La mort del duc de Calàbria, 1561). 
(45) Hablan mucho en que se arman navios en Lisboa, y que desde Madrid escribió un hombre de importancia a un mercader español de Cáliz (Calais)... (Epistolario de Luisa de Carvajal y Mendoza, 1612).

(46) Estimada madre: en el correo anterior remití a Vmd una carta, la que entregué a un amigo para que la echara en el correo en La Coruña $a$ fin de que ahorara Vmd algo en el portte... (Die Korrespondenz spanischer Emigranten aus Amerika, 1791).

Negativa:

(47) ... determinaba de no lo dejar entrar a él ni a otro ninguno que viniese en la tierra, y quél estaba confiado que no haría otra cosa. Y así se fue, y que no pudo holgarse con cosa más porque ya temía la venida de acá... (Cartas de Pedro de Valdivia, 1550).

(48) ... mas no la remitiré [a] menos que Vuestra Merced no quede satisfecho de los derechos y gastos que ha causado, pues me avisa que no quería pagarlos [...] de aquellos que le corresponden para castigo de su mala correspondencia (Cartas del mercader Felip Moscoso, 1674).

(49) Yo salí a ello, como lo tengo ya ofrecido otras veces, y aun me arrojé a decir que para mayor seguridad de que no quedaría vuesa merced con ellas, que las inviaría a vender por acá (Góngora. Epistolario completo, 1620).

(50) Sólo teníamos 1 ej. que se llevó. Me dijo de que en vista de que no teníamos, él hizo directamente un pedido. Pero, como supongo que sólo por nuestro medio le servirán, harían falta, en este caso: 9 ej. Curso de Química, de Puig (Tú verás si conviene o se puede traer alguno más) (Correspondencia de Eugenio Granell con sus camaradas del POUM, 1949).

\subsubsection{Persona}

A diferencia de los predictores reseñados hasta el momento, que pondremos a prueba en el análisis de todas las construcciones incluidas en el estudio, los que siguen a continuación se reservan para el examen de algunos tipos particulares.

Entre estos, figura la persona gramatical, uno de los factores a los que se ha concedido una mayor atención en los últimos tiempos, especialmente por parte de quienes llevan a cabo un análisis conjunto de queísmo y dequeísmo, como fenómenos que, en su opinión, obedecen a idénticos condicionantes. Estas propuestas tienen una deuda particular con las ideas defendidas inicialmente por García $(1986)^{8}$ en un trabajo muy citado posteriormente, y en el que esta investigadora defendía el valor icónico de la preposición en los casos de dequeísmo, ya que con ella el hablante lograría distanciarse de su enunciado y asumir una actitud menos comprometida con lo expresado en él. Aunque esta tesis fuera criticada en su momento por un exceso de subjetividad y por estar basada en la interpretación

8 Esta autora amplía y revisa la hipótesis del distanciamiento, formulada inicialmente por Bentivoglio/D’Introno (1977). 
de unos pocos ejemplos a partir de la introspección de la analista (López Morales $2004,75)$, lo cierto es que ha tenido un amplio eco en los estudios posteriores sobre ambos fenómenos (para otras propuestas funcionalistas basadas en esta idea del distanciamiento y algunas de las críticas posteriores cosechadas, ver supra §2.2.1).

En un intento por operacionalizar de una manera objetiva este sentido icónico de la preposición, Schwenter (1999) propuso vincular el análisis de este factor a la persona del verbo, a partir de principios como la evidencialidad (véase en el mismo sentido, Guirado 2009). En su opinión, la presencia de la preposición de ante que, tanto en los casos de queísmo como en los de dequeísmo, es un recurso de evidencialidad mediante el cual el hablante indica que la fuente de la información no es él mismo. Si ello es así, la relación con las personas de la comunicación resulta clara: el recurso a la preposición será mayor en la 3. a persona de los verbos, ya que de la información codificada en esta el hablante no puede hacerse responsable directamente. En el extremo opuesto, la ausencia de la preposición será más frecuente con la $1 .^{\mathrm{a}}$ persona, dado que el hablante es ahora plenamente responsable de esa información. Por último, en una posición intermedia quedaría la 2. ${ }^{\text {, }}$ la persona del interlocutor, más cercana al emisor que la 3. ${ }^{\text {a }}$ persona, pero cuya fuente de evidencialidad no puede equipararse con la del hablante.

De hecho, el estudio llevado a cabo por este autor comprueba una gradación en este sentido. La 1. ${ }^{\mathrm{a}}$ persona favorece las elisiones (.69), seguida por la 2. ${ }^{\mathrm{a}}$ (.48), y con la $3 .^{a}$ persona como el entorno más desfavorable (.27). Otros trabajos oponen conjuntamente las ocurrencias de la $2{ }^{\mathrm{a}}$ y la $3^{\mathrm{a}}$ persona (.46) a las de la $1 .^{\mathrm{a}}$ (.64), como hace Mollica (1991) en su estudio del portugués. ${ }^{9}$ Y no faltan autores que distinguen entre las referencias del singular y el plural en algunas de estas personas. Así, en su investigación sobre el corpus PRESEEA de Valencia, Gómez Molina (2013) observa nuevamente contribuciones elevadas para la variante cero en la $1 .^{\mathrm{a}}$ persona, pero tan solo en singular (.67). Curiosamente, sin embargo, la 1. a persona del plural, en la que también participa el emisor, arroja los datos más desfavorables de todos (.25).

Aun así, otros estudiosos han descartado la hipótesis funcionalista a partir de los datos obtenidos en sus investigaciones. Así, Almeida (2010) señala no encontrar diferencias significativas relacionadas ni con la persona del verbo, ni con la fuente y dirección de la información en su análisis del dequeísmo en el habla de Tenerife. Del mismo modo, Bentivoglio/Galué (1998-1999) desechan también la hipótesis de la iconicidad en su investigación sobre el español de Caracas, con resultados que difieren de los hallados por Guirado (2009) en esa misma comu-

9 En este trabajo se distingue un tercer contexto, el de las referencias impersonales, que obtiene los pesos explicativos más desfavorecedores para la elisión (.38). 
nidad de habla. Finalmente, tampoco Kanwit (2015) encuentra resultados significativos relacionados con la persona en la capital venezolana, aunque sí mayores frecuencias de inserción pronominal en la $3 .^{\text {a }}$ persona.

Para valorar estas hipótesis en la historia del español, hemos codificado también los ejemplos de la muestra de acuerdo con la persona gramatical del verbo. Distinguimos, a este respecto, entre las formas de la $1 .^{\mathrm{a}}$ persona, como en (51) a (54), la 2. ${ }^{\mathrm{a}}$ persona, ${ }^{10}$ como en (55) a (58), y la $3 .^{\mathrm{a}}$ persona, como ilustran los ejemplos de (59) a (62). ${ }^{11}$

Ahora bien, a diferencia de otros trabajos en los que el factor se ha analizado tan solo en relación con los complementos verbales, en nuestro estudio hemos incluido también aquellos casos en los que la subordinada completiva funciona como complemento de una estructura colocativa compuesta por un verbo soporte y un sustantivo, como en (54), (60) y (62), o un verbo copulativo y un adjetivo, como en (52) y (56). Nuestra hipótesis, en este sentido, es que las restricciones semántico-cognitivas que pueden operar en relación con la persona en un verbo simple como advertir en (51) no deben de ser muy distintas de las que intervienen en expresiones como estar seguro o tener duda, en (52) y (54), respectivamente.

\section{1. ${ }^{\mathrm{a}}$ persona:}

(51) Es cuanto tengo que decirle a V.M, SSSS, e hijo que lo estima de corazón y pide rendido su bendición. Pedro del Toro. Nota: Advierto a V.m que la carta que me dirigió y que contesto no tiene fecha (Puerto Rico en el siglo XIX a través de las relaciones epistolares, 1811).

(52) ... Si Vd. pudiese emplearlo en alguno de esos canales, habiendo faltado Lemaur, según he visto en la Gaceta, o algunas otras obras, estoy seguro que algún día me daría Vd. las gracias (Epistolario de José Nicolás de Azara (1730-1804), 1785).

(53) Exmo. Señor. Me alegro de que V. Ex. se [h] aya divertido. Yo echava menos los preceptos de V. Ex., pero no carecía de las buenas noticias de su salud (Gregorio Mayans, en Juan Basilio de Castellví y Coloma, Conde de Cervellón. Epistolario, 1736).

(54) ... porque (arguyendo de lo que ya hemos, sin mérito nuestro, experimentado de su piadoso y paternal afecto) no tengo la menor duda de que no se interese en favorecer a nuestro Ilustrísimo en su pretensión en la Corte de Nápoles (Alejandro Cameron, en Epistolario de Pedro Rodríguez Campomanes, 1781).

10 Incluimos aquí todos los casos en los que el referente identifica al interlocutor, ya se trate de formas específicas de la 2. ${ }^{a}$ persona-(tú) cantaste, (vosotros) cantasteis-, ya de formas deferentes codificadas mediante pronombres (usted, vuestra merced...) y afijos ([usted] cantó) de la 3. ${ }^{\mathrm{a}}$ persona.

11 En todos los casos, agrupamos en cada persona tanto las referencias al singular como al plural. 


\section{2. ${ }^{\mathrm{a}}$ persona:}

(55) Pues yo soy el falangista. ¿Te acuerdas que el día de nuestra partida para Valladolid yo me quise quedar por tu culpa? (Luis Sánchez Moro, en Madrina de guerra, 1938).

(56) ... y así vuestra merced viva seguro que le seré agradecido y corresponderé a sus finezas, pues ha sido Dios servido de ponerme en estado de poderlo hacer (Cartas desde América, 1700-1800, 1722).

(57) Todo mi consuelo lo tengo en Vm y q[u]e no perderá Vm un instante en persuadir a mi muger $a q[u]$ e sin pérdida de tienpo se ponga en marcha para q[u]e mi espíritu de una vez descanse y viva yo feliz (Die Korrespondenz spanischer Emigranten aus Amerika, 1789).

(58) ¿Sería $V d$. tan amable que quisiera cuidarse de que alguien hiciera una nota bibliográfica y enviarme el recorte cuando se publicara? Mil gracias, perdone 1a molestia (Ángel Ossorio y Gallado, en Un catalanófilo de Madrid, 1932).

\section{3. ${ }^{\mathrm{a}}$ persona:}

(59) El embajador no me había contestado para darme las gracias de esta comunicación cuando hace pocos días, cuando los diarios empezaron a hablar que el pintor Sorolla estaba haciendo el retrato de los Reyes (Pedro Gil, en Epistolarios de Joaquín Sorolla, 1907).

(60) ... me contó como es verdad que el frayle le contó como vio si[e]te civdades muy grandes de piedra y las portadas de turquesas y que tiene noticia que en otras civdades ay vasijas de oro (Desde la otra orilla, 1539).

(61) Mi querido amigo, no debiendo escribir á V. en este momento porque cuando la pluma trata de estampar un juicio debería aguardar á que la emocion le permitiese hacerlo, sino atinada, al menos clara y lógicamente (Epistolario de Fernán Caballero y Eugenio Hartzenbush, 1860).

(62) Yo le creía a V. bien lejos de su patria, pues antes de mi salida de Bar[celo]na (a donde no sé cuándo volveré) rumores corrían de que ya le teníamos en un buen vicariato y allí dirigiendo y trabajando a medida de sú gusto (Cartas de San Enrique de Ossó y Cervelló, 1886).

\subsubsection{Tiempo}

Las interpretaciones funcionales acerca de fenómenos como el queísmo y el dequeísmo han considerado también la potencial relevancia del tiempo de la cláusula regente, ya que, a juicio de algunos autores, este puede medir también el mayor o menor distanciamiento del emisor con respecto a los enunciados que expresa. En este sentido, una hipótesis de partida es que las formas diferentes del presente encierran un mayor distanciamiento que este, al trasladar los procesos referidos por el verbo a tiempos pasados o futuros, sobre los que se tiene un menor control (Martínez Sequeira 2000). Entre estas formas temporales, algunos autores han privilegiado las del pasado como principales responsables de la inserción preposicional. Así lo hace, por ejemplo, Guirado (2009), quien, en su estudio sobre el habla de Caracas encuentra menos elisiones con las formas del pretérito $(61 \% ; .43)$ que 
con las del resto (78\%; .57). En el mismo sentido, Schwenter (1999) obtiene índices elevados de inserciones cuando el verbo de la clásula regente está en pasado (.68), frente a valores casi neutros del presente (.49) y levemente desfavorecedores del futuro (.47). Para este autor, dado que de es un marcador de fuente de información, es justificable que aparezca más frecuentemente con verbos en pasado. Sin embargo, esta interpretación parece contradecirse con los resultados obtenidos en la misma muestra en los casos de queísmo. En estos, la ausencia de la preposición está también alentada por las formas del pasado (.61), seguidas de nuevo por el presente (.55) y con el futuro una vez más con el peso explicativo más bajo (.44). ¿Queísmo y dequeísmo, dos fenómenos inversos, alentados por los mismos condicionantes, y con la misma dirección explicativa? A las dificultades para responder a esta pregunta se suma el hecho de que otros estudios no hayan encontrado correlaciones significativas con este factor, como sucede en el análisis del queísmo en Valencia (Gómez Molina 2013, 217) o en el dequeísmo en Tenerife (Almeida 2010).

Dada la diversidad de resultados y de formas de configurar un predictor ${ }^{12}$ en el que, además, intervienen tantos niveles diferentes, ${ }^{13}$ en el presente estudio partimos de la hipótesis inicial, esto es, la distinción entre el presente de indicativo, tiempo mayoritario en el corpus, y sobre el que el hablante ejerce un mayor control, y el resto de las formas verbales, ya remitan al pasado o al futuro. Por otro lado, del mismo modo que en el caso de la persona, el factor se incluye en el análisis de las completivas dependientes de verbos, pero también de aquellas que complementan a categorías nominales en estructuras colocativas con verbo soporte o atributivo. Los siguientes son algunos ejemplos representativos:

\section{Presente:}

(63) ... y luego comenzó a venir gente al estudio, 9 o más fueron las visitas que tuve, entre ellas las del hijo de Martos (o sea el que hirió a Canalejas) me entero que desea pronto los retratos de sus hijos y yo le he pedido me deje terminar lo que comencé ayer (Epistolario de Joaquín Sorolla a Clotilde Sorolla, 1891).

(64) ... ya estoy mas conoscido aca que no alla hago quenta que mi conpadre si conprare nabio el trayra orden con que vengays con el mechior que no conmigo asta otros maridos

12 En algunos trabajos, presente, pasado y futuro aparecen como factores independientes, mientras que, en otros, el pasado se opone al resto.

13 En este sentido, cabe plantearse también cómo considerar el tiempo: ¿de acuerdo con un criterio morfológico, que distingue entre los diferentes paradigmas de la conjugación? o ¿conforme a un parámetro semántico? Por poner un par de ejemplos-en absoluto únicos-, ¿cómo conceptualizar las formas del presente que expresan sentidos traslaticios, como el pasado o el futuro? o ¿qué ocurre con los usos del futuro que no expresan realmente futuro, sino sentidos modales? Es esta una cuestión relevante que, sin embargo, suele pasarse por alto. 
sintiendo los trabajos de España no quieren yr alla (Cartas de particulares en Indias del siglo XVI, 1594).

(65) ... tiene obligación a cumplirlo siendo cosas de comunidad, y más misas dichas por las ánimas, que yo me persuado a que esotro está satisfecho mediante los gastos que Vm. Me decía otras veces hacía esta persona (Sor Ángela Marroquino, en Cartas de Sor Ángela María de la Concepción, 1679).

(66) Es urgente su venida a comienzos de Diciembre. Con que ya sabe que le esperamos. Entregué el plano y todas las notas, me parecía lo mejor, pues están de acuerdo en que su opinión debe guiar las decisiones (Epistolario de Antonio Gallego Burín, 1924).

Otros:

(67) ... Adonis me mando cosas pero escribir ni hablar me mando aviso que fuera á Pontevedra cuando pudiera que El aca no podia venir (Una familia y un océano de por medio, 1960).

(68) Convinieron todos en que no habia duda de que era aquel el Pepiri, el que siempre era Rio muy considerable aunque á la sazon le viessemos pocas aguas, las que igualmente se veran en el mismo Uruguay (Diario de la frontera hispano-lusa, 1752).

(69) Habíanle escrito sus hermanas: «Ves que está enfermo el que amas», y aguardó a que le escribiesen: «Señor, si estuvieras aquí, mi hermano no hubiera muerto» (Epistolario completo de don Francisco de Quevedo Villegas, 1635).

(70) Querido Juan: Sólo con la llegada de tu carta del 19 de enero 49 caía en la cuenta de que la última vez que tuve noticias tuyas fue hace justamente un año. No es que te haya olvidado ni que aplicase represalias (Correspondencia de Eugenio Granell con sus camaradas del POUM, 1949).

\subsubsection{Preposición}

Como ya se ha indicado, en el análisis histórico del queísmo, el interés no puede centrarse solo en la presencia o ausencia de la preposición de, por muy mayoritaria que esta sea en el discurso, y por mucho que se trate de la partícula a la que se han limitado numerosos estudios en el español contemporáneo (Alcaraz Varó/ Martínez Linares 1997, 477; Almeida 2009a: 10; Ueda 2017, 1). Las razones son varias. Por un lado, en el queísmo pronominal estudiado en estas páginas, ese papel protagonista no lo desempeña de, sino en. Por otro lado, salvo en el grupo de las locuciones, donde el uso de de es prácticamente categórico, esta preposición alterna en determinados casos con otras, como $a$, con, por o en. ${ }^{14}$ En ocasio-

14 Algunos trabajos sobre el español actual en los que se tienen también en cuenta estas partículas son los de McLauchlan (1982, 15); Boretti de Macchia (1989, 27); Carbonero (1991, 44); Gómez Molina/Gómez Devís (1995, 196); Del Valle (1996-1997, 804); Gómez Molina (1996, 81); Bentivoglio/Galué (1998-1999, 140); Gómez Torrego (1999, 2133; 2006, 335); Rabanales (2005, 47 y 51); RAE/ASALE (2005; 2009, 3248); Guirado (2009, 19); San Martín (2016, 208), entre otros. 
nes, el uso de unas y otras preposiciones está íntimamente ligado a la rección de ciertas unidades lingüísticas, que presentan usos invariables a lo largo de la historia. Sin embargo, en otras, la subcategorización de estas palabras ha sido más variable, de tal manera que la preferencia por una preposición no ha impedido la pugna con otras en algunos momentos de la historia. Así, el verbo confiar aparece unido generalmente a la preposición en, pero en el corpus encontramos no pocos ejemplos con de, como en (71), e incluso con la partícula con, como en (72). Y ello, como puede verse, a lo largo de toda la historia.

(71) ... el que mas os desea ver q escrevir vro marido savastian de llerena no enbio poder porqstoy confiado de que hareys lo que os enbio a rogar y q no sera menester (Cartas de particulares en Indias del siglo XVI, 1567).

(72) Confiando con que estudiarán con el mayor interés nuestra propuesta, y en la espera de una respuesta suya a la mayor brevedad posible, nos complacemos (Correspondencia de Eugenio Granell con sus camaradas del POUM, 1948).

Lo mismo sucede con el sustantivo orden, cuyas subordinadas alternan entre las preposiciones de, en e, incluso, $a$, como revelan los fragmentos siguientes, repartidos también por periodos diversos:

(73) Tuvo que abandonar el trabajo porque con motivo de haberse instalado allí el gobierno polaco, las autoridades dieron orden de que todos los extranjeros salieran de la población. Tuvo que venir aquí, que es su residencia habitual. (Juan Andrade, en Correspondencia de Eugenio Granell con sus camaradas del POUM, 1939).

(74) ... y estar [en]fermo y no poder yo a çer por mi p[er]sona lo que quisiera por la mucha [en] fermedad que me a suçedido acorde de dar orden en que vm pase en estas partes (Cartas de particulares en Indias del siglo XVI, 1571).

(75) ... pues todo mi anelo no es más que a dar descargo de mi persona, i por si acaso se me proporsionare viaje por España estimaré que Vmds. den orden a que en Cádis resiban por Vmds. dinero o cacao, que es lo que ago intensión (Correspondencia canario-americana, 1773).

Y la misma variabilidad se advierte con otros sustantivos como miedo (miedo de que, miedo a que), temor (temor de que, temor a que), confianza (confianza (en) que, confianza (de) que), esperanza (esperanza (de) que, esperanza (en) que), entre otros.

Limitado, pues, al análisis de verbos y categorías nominales, en el presente estudio analizaremos la potencial influencia de dos entornos sintácticos. En el primer caso, nos encontramos con unidades que seleccionan categóricamente de a lo largo de la historia, y de las que (76) a (79) son ejemplos representativos. Por otro lado, bajo la categoría de Otras agrupamos tanto los ejemplos en los que el papel protagonista es desempeñado por otra preposición, como aquellos en los que la preferencia por de no impide la alternancia con otras partículas, como 
hemos visto en los fragmentos anteriores. Como es lógico, en este último caso esa alternancia será valorada en cada periodo histórico. ${ }^{15}$

\section{Preposición de:}

(76) ... y os lleue algun refresco para essotra nauegaçion questa en la ciudad de altamira y es cura alli y me auissa (de) que gana alli muy poco y ansi me inbia vna informacion del tienpo q ha estado alli (Cartas de particulares en Indias del siglo XVI, 1595).

(77) ... a quien suplico os persuada a que creays de mi os e pagado con uerdadero amor y deseo del alma de boluer muchos años a sino que mis pecados an sido causa (de) que yo no goçase de todo mi bien (Cartas de particulares en Indias del siglo XVI, 1590).

(78) Con el motivo de que mi compañero D[o]n Francisco de Albizuri ha renunciado en mí los empleos que tenía en esta ciudad de m[aes]tro armero de esta ciudad... (Die Korrespondenz spanischer Emigranten aus Amerika, 1801).

(79) ... que pues se estan solas mis hermanas no falte vm de cassa no tengo que avisar mas de $q$ vm mire por todo y en esto del retablo y de la lampara se ponga mucha dilijençia en que se ponga [en] su lugar (Cartas de particulares en Indias del siglo XVI, 1578).

\section{Otras:}

(80) ... a la dha ysla spanola e çiudad de sto domjngo muy pocas vezes ay nabio de derecho viaje y acaesçe estar ocho o diez meses aguardando (a) que aya nabio para el dho viaje (Documentos para la historia lingüística de Hispanoamérica, 1549).

(81) Porque Ataúlfo, rey de los longobardos, insistió con el papa (en) que todos los vasallos de la iglesia le pagasen una moneda y sobre ello le hizo guerra, le castigó Dios en matarle con un rayo (Memoria manuscrita, 1574).

(82) ... nos tratan con la mayor ignominia, y como si fuéramos esclavos nos obligan a asistirles sin pagarlo, y si nos resistimos, como es justicia y razón, nos amenazan (con) que nos meterán en un calabozo y nos pondrán grillos (Carlos Rodríguez, en Epistolario de Pedro Rodríguez Campomanes, 1782).

(83) En cuanto recibí tu parte aquí, corrí al telégrafo para ponerte uno, y me encontré con que están las líneas interrumpidas, por efectos del temporal de anoche (Correspondencia de Benito Pérez Galdós, 1894).

Como vimos en otro lugar, algunos autores que apuestan por las tesis funcionalistas como eje de la variación han señalado que el distanciamiento comunicativo que, icónicamente, introduce la preposición, es especialmente factible con el auxilio de la partícula de. Aunque de una manera no siempre coincidente, en la bibliografía se ha hablado a este respecto de su carácter más polisémico (McLauchlan 1982, 15), cuando no impreciso (Guirado 2009, 19) o carente de significación alguna (Bogard/Company 1989, 269; Company Company 1991, 118). Sea

15 De hecho, las mayores muestras de esa variabilidad se observan en el periodo clásico, en el que la fijación de la lengua no alcanza todavía los niveles del periodo moderno, y menos aún, los del contemporáneo. 
como sea, todo ello permitiría a de funcionar como un mero elemento de relación. Asimismo, Herrero Ruiz de Loizaga (2005, 91) sostiene que, en la historia, ha habido una mayor tendencia al empleo de las preposiciones cuando estas no eran de. En consecuencia, tomaremos esta hipótesis como punto de partida en la investigación empírica.

\subsubsection{Grado de fusión}

En las completivas dependientes de sustantivos y adjetivos, deseamos comprobar también la relevancia que puedan adquirir ciertas combinaciones sintácticas en las que estas unidades suelen aparecer. En el caso de los sustantivos, ejemplos como los de (84) y (85) ilustran la asociación desde antiguo del sustantivo duda con estructuras impersonales con el verbo haber. Sin embargo, este mismo sustantivo en (86) y (87) aparece en entornos sintácticos distintos, ajenos a las ataduras de este verbo soporte y otros del mismo tenor (tener o caber). Dada la mayor fusión sintáctico-semántica en el primer contexto que en el segundo, cabría pensar que hubiera también una correlación directa con los índices de queísmo. De hecho, en la vuelta al «esquema primitivo» (queísta) que algunos autores indican que está ocurriendo en el español actual (Bogard/Company 1989, 262-264; Leonetti 1999, 2088) se menciona explícitamente este tipo de construcciones con verbo soporte en las que estructuras como «darse cuenta que», «tomar conciencia que», «tener miedo que», «tener la seguridad que» se reanalizan como un verbo complejo, formado por un verbo y un sustantivo, más una subordinada. Y quizá no por casualidad, las autoridades académicas consideran hoy correctas algunas de ellas, como sucede con las combinaciones entre el verbo dar y ciertos sustantivos de reacción afectiva (miedo, pena, etc.) (RAE/ASALE 2009, 3253). Por otro lado, estas hipótesis se han visto reforzadas por algunas investigaciones sobre comunidades de habla contemporáneas, en las que se han confirmado tales diferencias, como revelan los datos de Almeida (2009a) en Tenerife, Gómez Molina/Gómez Devís (1995) en Valencia ${ }^{16}$ o Arjona (1978) en Ciudad de México.

16 Aun así, los datos más recientes de Gómez Molina (2013) sobre esta misma ciudad muestran diferencias mucho menores ( $38 \%$ vs. $35 \%$ ). 


\section{Sustantivos en estructuras con verbo soporte:}

(84) ... quedaron pendienttes todos los libramientos de reditos de censos que deuian pagarse en 8 de junio de los que ymportaran 80500 rreales, y no ay duda que esttos acudirán a la thesoreria a prettender su cobranza (El castellano de Bilbao en el siglo XVIII, 1742).

(85) ... y me respondieron que sí, fundándose en la fuerza del derecho natural. No hay duda de que si se les concediese la licencia vivirían más gustosos y no se experimentarían los quebrantos que puede ocasionar su deserción (Epistolario 1777 a 1821 de Juan José y Fausto Delhuyar, 1790).

\section{Otros:}

(86) ... avnque bien se yo que si a otro alguno de mys parientes que biniesen lo arian no me quiero detener porque scriuo con duda q sea vm biua (Cartas de particulares en Indias del siglo XVI, 1569).

(87) ... persona que thenia experiencia para el modo que se podia thener para linpiar y secarlos se encargase dello, y aunque condesendio en ello pero con arta duda de que pudiesen thener el rremedio necessario para que pudiesen quedar linpios y secos de manera que fuesen de prouecho (Bilbao en sus documentos, 1651).

Parecidas restricciones se analizan entre los complementos de adjetivos. En un extremo situamos a aquellos que aparecen en estructuras atributivas, como las ilustradas en (88) y (89), muy frecuentes en el discurso, y en las que el adjetivo actúa como el verdadero núcleo del predicado nominal. El resto de adjetivos, ejemplificados en (90) y (91), representan el contexto opuesto. Las hipótesis en este caso son similares a las esbozadas arriba: las soluciones queístas serán más frecuentes en el primer contexto, dada la particular fusión del adjetivo con la estructura atributiva en la que se inserta, mientras que el entorno contrario será más adverso para las elisiones.

\section{Adjetivos en estructuras atributivas:}

(88) ... de suerte que en beces perdió poco más o menos de cinco a seis mil pesos y de presente lleuará cosa de cinco mil en contado y para que vms. estén adbertidos que el ymbentario que se hiço resa de muy poca cantidad pero la verdad que se ocultó la mayor parte de los bienes y no se ymbentariaron (Vida y fortuna del emigrante navarro, 1636).

(89) Esté Vm. seguro que yo mismo en desempeño de las confianzas que de Vm. he merecido en todos tiempos haré fijar carteles (Correspondencia canario-americana, 1798).

\section{Otros:}

(90) ... vastimientos y demas cossas que para ella tengo prebenidos hasta que su magestad o Vuestra Senoria en su real nombre otra cossa hordene y mande, satisfecho que como tan catolico y cristianisimo principe no permitira que resciva yo tan notable agrabio (Juan de Oñate protests against the injustice of the suspensión, 1596). 
(91) Mui señores míos: Doy respuesta a sus dos apreciables, 12 de noviembre del año pasado y 28 de junio del presente, advertido de que havían Vmds. recibido la mía de 20 de agosto y de que no me estienda a más suplementos a favor de D. Matías Domingo Hernández ( $A l$ recibo de esta, 1793).

\subsubsection{Relación paradigmática}

Con este factor deseamos poner a prueba las hipótesis acerca del potencial arrastre que las soluciones queístas en determinadas categorías sintácticas podrían ejercer sobre otras unidades formal y semánticamente relacionadas. De ser ello así, un sustantivo como confianza en (92) debería mostrar índices de queísmo similares a los del verbo confiar con el que está relacionado (93), y diferentes de aquellos en los que tal relación no existe, como sucede con otros nombres como gana(s) en (94) y (95). Esta hipótesis se someterá a evaluación en los complementos de categorías nominales (sustantivos y adjetivos) y verbales, no así en las otras dos construcciones (locuciones y oraciones relativas). Así las cosas, el predictor se divide en los siguientes dos niveles:

\section{Relación paradigmática:}

(92) Vuesa merced solo, que ha comenzado y proseguido el aventurar hacienda en mi favor, es quien ha de tener valor para [no] dejarme, y confianza que no he de ser tan desgraciado que se me despinten o hábito o pensión que tengo pedidos (Carta de Góngora a Cristóbal de Heredia, 1622).

(93) Decisiete días he estado en una cama con tan recias calenturas que entendí que era el último tiempo de mi vida, y cierto que sólo me pesaba de perderla donde no viese la cara de V.E. y le encomendase esos pedazos de mi sangre; que era fuerza que quedasen en tanto desamparo, aunque de la benignidad de V.E. confiaba que no los desampararía (Carta de Lope de Vega al duque de Sessa, 1616).

\section{Otros:}

(94) Mi querida Clotilde. Ganas tenía verdaderamente que se confirmase la primera medalla, así que estoy contento (Carta de Sorolla a Clotilde, 1892).

(95) yo también tengo ganas de que vengas y estoy deseando llegue el día 6 para abrazarte y darte muchos besos (Carta de Clotilde a Sorolla, 1895).

\subsubsection{Determinación}

Limitado exclusivamente al análisis del queísmo en los complementos de sustantivos, tanto en completivas dependientes de categorías nominales como en 
las oraciones de relativo, distinguimos nuevamente dos niveles: la posibilidad de que el sustantivo esté acompañado por el artículo determinado, un contexto mayoritario en el discurso, frente al resto de opciones.

\section{Artículo determinado:}

(96) ... y que a todos había parecido siempre que no lo debía hacer, y le habían encargado la conciencia que no lo hiciese, porque se seguirían mayores daños (Escritos Menores/José de Acosta, 1592).

(97) Y si no azertara a estar en la corte el licenciado don Cristóval de Vargas, que dixo el año que nazi, no me admitieran, porque me mandaron dar más información (Juan de la Cueva, en Correspondencia privada de Diego de la Cueva y su hermano Juan, 1608).

(98) ... y es menester malbaratar todos los trastes que tengo, que si vendiéndoles con estimación dan seis, tirando a salir de ellos no darán ni dos. Y con la esperanza de que vendrías, según tu palabra, ya tenía compradas diferentes cosas para el uso de casa y de tu gasto (Cartas desde América, 1700-1800, 1763).

(99) Su grata de ayer que me apresuro á contestar me apura aun más de lo que estaba antes de salir de Madrid: la situación en que me encuentro que someto á su claro juicio es la siguiente... (Duque de T’Serclaes, Epistolario de Menéndez Pelayo, 1910).

\section{Otros:}

(100) Muy señor mio: ayer mañana para cuando salió la Micaela para esa dieron orden que para las dos horas se desocupase toda la havitación del suelo principal (Muestra del castellano norteño, 1834).

(101) Suministré las fuerzas del Destacamento por el espacio de dos meses que allí estuve, así como las que pasaban a operaciones por aquella zona (La pérdida de Filipinas narrada por un soldado extremeño, 1899).

(102) El Papa estaba entonces en manos de los franceses, y aunque hubo algún rumor de que Pío VII había señalado para esta dignidad de senador de Roma, según unos a su hermano y según otros a su sobrino, casado con una señorita... (Diario de 1814 y 1815: el final del destierro y la restauración de la Compañía de Jesús, 1815).

(103) Puedes suponer mi contento. He dormido bien después de dos días en que todo [en] ellos anduvo muy mal, y sobre todo la comida que fue muy endeblita, llegando a no estar bien (Epistolario de Joaquín Sorolla a Clotilde Sorolla, 1909).

Especial interés posee el análisis de este predictor en el queísmo pronominal, dado que, a partir del siglo XVIII, las oraciones de relativo oblicuas comienzan a introducir el artículo determinado junto al pronombre (Girón Alconchel 2004). En relación con este hecho, en un trabajo anterior (Blas Arroyo/Vellón 2018) hemos comprobado que, sobre todo a partir de los siglos XIX y XX, la presencia de ese mismo artículo en el antecedente, como en (104), desalienta su duplicación junto al relativo. Por el contrario, casos como los de (105), en los que el antecedente no va acompañado por el artículo determinado, actúan en sentido contrario. La hipótesis es, pues, que estos últimos contextos deberían favorecer las inserciones 
preposicionales, dada la especial fusión que en ellos se advierte entre la preposición y la combinación el que:

(104) ... se inicia entre los últimos meses de 1777 y los primeros de 1778, cuando llegan a Freiberg, hasta el mes de Marzo de 1781, en el que, terminados los estudios en la Bergakademie, pasan a Viena... (Epistolario 1777 a 1821 de Juan José y Fausto Delhuyar, 1783).

(105) ... y avergonzado de mis pueriles cobardías, lleno de insólito valor y atropellando humanos miramientos, hubo un día en el que, sin presentarme nadie, sin otro título ni autorización que mis propios entusiasmos... (Manuel Martínez, en Epistolario de Menéndez Pelayo, 1909).

Por otro lado, en las construcciones conjuntivas, algunos autores han llamado la atención acerca de la particular frecuencia de las secuencias con que (sin preposición) en ciertos contextos sintácticos en los que el sustantivo va precedido por el artículo (Arjona 1978; McLauchlan 1982; Rabanales 2005). Este hecho, observable, por ejemplo, en expresiones formadas por artículo + sustantivo + ser (la pena es que...; el ideal sería que...), podría actuar también en las completivas analizadas en este estudio, favoreciendo así las soluciones queístas.

\subsubsection{Función sintáctica}

Reservado en exclusiva al análisis del queísmo pronominal, en el estudio valoraremos la posible incidencia en la variación de la función sintáctica desempeñada por el antecedente. Dado el carácter semántico de los sustantivos que desempeñan este papel, que, como se recordará, encierran en todos los casos sentidos temporales y locativos (ver supra §3.2.1), la función predominante en el corpus es la de complemento circunstancial, ejemplificada en (106) y (107), a continuación. A esta corresponde el 65\% $(n=1445)$ de todas las ocurrencias de la variable lingüística. El 35\% restante se reparte de manera desigual entre otras funciones, como las de sujeto y complemento directo en (108) a (109), respectivamente. A los efectos del análisis de regresión, todas ellas se agrupan en un mismo bloque, que se opone al anterior.

\section{Complemento circunstancial:}

(106) Y a mi hija que le escriba a su madre y a mí en todas ocasiones que salgan navíos de ese reino para éste. Y vuestra merced reciba muchas memorias de mi ahijado Francisco de Molina (Cartas desde América, 1700-1800, 1725).

(107) Oh Dios de paz, debemos decir, y cómo el enemigo procura sacar partido en este santo tiempo en que más debíamos trabajar para vivir en paz, para turbarnos e inquietarnos y obrar de distinto modo a como tú quieres que obremos (Epistolario personal de Sor Ángela de la Cruz, 1887). 
Otras:

(108) A eso de quien calla, otorga, añadimos: No es consentir cuando se otorga por fuerza. ¡Viva el día que podremos responder dando la cara! (Francia no nos llamó, 1939).

(109) ... y que me huelgo que aya auido ocasion en que servirle que si dios fuere seruido quando yo baya llevare el hilo (Cartas de particulares en Indias del siglo XVI, 1590).

Gutiérrez Araus (1985, 15-36) advierte que, en el primer contexto, esto es, cuando el antecedente desempeña el papel de circunstancial, el relativo no es necesario (Había bebido mucho la noche (en) que lo detuvieron), por lo que se considera un entorno especialmente propicio para las elisiones (en el mismo sentido, véase Alonso Megido 1981-1982), una hipótesis que someteremos a prueba en la historia del español.

\subsubsection{Tipo de relativa}

Igualmente reveladora para el análisis del queísmo pronominal puede ser la distinción entre los dos bloques de oraciones de relativo que distingue habitualmente la gramática. El desequilibrio muestral observado en el párrafo anterior se incrementa aquí, como demuestra el hecho de que un $86 \%$ de todas las relativas del corpus corresponda a las oraciones especificativas. Estas, que forman grupo fónico con el antecedente, restringen su extensión semántica, como se aprecia en (110) y (111). Por el contrario, las oraciones explicativas, minoritarias en el corpus (14\%), componen un grupo fónico propio, dado que su función no radica en limitar la referencia, sino en aportar informaciones adicionales sobre el antecedente (Brucart 1999, 408-417).

Especificativa:

(110) yo os doi liçençia para q los podais mandar esta cantidad y yo lo cunplire y a esto me podeis obligar q se los dare dende el dia q viniere o dende el dia q tomare puerto la nao (Cartas de particulares en Indias del siglo XVI, 1567).

(111) ... me impresionó verdaderamente al leerla, sobre todo el final, que me gustó al máximo la noche que lo leí. (Hablo del final de la primera parte; no confundamos). (Correspondencia de Benito Pérez Galdós, 1888).

\section{Explicativa:}

(112) ... y por haverse rompido la roldana con que se subía, quedó colgada a media altura de la torre, sostenida con escoras, hasta el dia sigte, que se preparó otra y se acabó de subir, cuia campana no duró sino hasta el mes y dia 19 de abril del siguiente (Memorias de un menestral curioso, 1791). 
... no es verosímil que tan presto se hubiese dado a otro la comisión de ordenarlos y publicarlos, pues el año 1590, en que Acosta publicó su célebre obra, ya Recho había acabado su compendio (Epistolario de José Nicolás de Azara (1730-1804), 1785).

También en esta ocasión, la especial frecuencia de los contornos especificativos en el corpus analizado podría favorecer las variantes tradicionales, esto es, el queísmo pronominal. Por el contrario, cabe especular inicialmente con que las menos recurrentes oraciones explicativas podrían suponer un vector favorable para las inserciones preposicionales.

\subsubsection{Origen gramatical}

Concluimos esta relación de factores lingüísticos con dos factores sintácticos que reservamos exclusivamente para el análisis de las locuciones. En el presente caso, consideramos la posibilidad de que la categoría gramatical de la palabra que actúa como cabeza de la construcción pueda influir significativamente en la variación. Para ello planteamos dos niveles. Por un lado, las locuciones cuyo núcleo es un sustantivo, como en (114) y (115). Por otro, aquellas en las que ese papel es desempeñado por otras clases de palabras, como el adverbio en (116) y (117). Inicialmente, cabe postular la hipótesis de que el menor grado de gramaticalización de las primeras podría favorecer la conservación del nexo preposicional, mientras que una gramaticalización mayor de las segundas haría este más superfluo y, por tanto, podría convertirlas en aliadas de las variantes queístas.

Sustantivo:

(114) El cuadro del Senado va volando y estoy contento de él, hasta el punto que lo hago a gusto (Carta de Sorolla a Clotilde, 1892).

(115) Tú sabes que yo depongo mi voluntad ante lo que más convenga para vosotras, aquí frío no hace, hasta el punto de que no se enciende más que el chubesqui en el estudio dejándolo apagar al cuarto de hora (Carta de Sorolla a Clotilde, 1891).

Otras:

(116) Grocio, Seldeno i Pufendorf a quienes los Modernos veneran como Maestros del Derecho de Gentes erraron en no establecer el Derecho Natural en las Leyes de la Divina Providencia, que antes que huviesse lei escrita, mandavan que los Hombres viviessen en Religión (Carta de Mayans a Nebot, 1740).

(117) En fin, ya parece que la Divina Providencia quiere colmar mis deseos antes de que la parca me consuma (Cartas desde América, 1791). 


\subsubsection{Posición}

Finalmente, con este último predictor deseamos medir la potencial relevancia de la posición que ocupa la subordinada introducida por la locución con respecto a la oración con la que está relacionada. Como muestran los siguientes ejemplos, dos locuciones adverbiales como antes (de) que y después (de) que pueden introducir cláusulas subordinadas tanto antepuestas, (118) y (119), como pospuestas, (120) y (121).

Antepuesta:

(118) ... y tuvieron tanta diligencia y cuidado en aprender la doctrina cristiana y confesarse, que antes que amaneciese andaban los caciques por las calles llamando a todos los indios, para que viniesen a la iglesia a aprender la doctrina y confesar (Diario de un oficial de la Guerra de la Independencia, 1813).

(119) ... yo siempre e tratado de darle buenos consejos para un bien de el, yo lamento que despues de que se caso aya estado tampoco (sic) tiempo en casa, tu me dices una cosa y el me dice otra (Cartas do destino, 1930).

Pospuesta:

(120) ... pense con lagrimas de my hojos de no la poder escrebir mas con la esperança q tengo en nuestro Señor dios que me hos dexara ver de mis hojos antes que muera (Cartas de particulares en Indias del siglo XVI, 1568).

(121) Dímosla en presençia del nunçio, después de q(ue) el P(adr)e fr(ay) Tomás de Jesús con çinco religiosos q(ue) tray consigo, avían fundado su conbento en esta ciudad (Epistolario de Ana de Jesús, 1610).

\subsection{Factores extralingüísticos}

Por lo que a los factores sociológicos se refiere, hay que reconocer que, a los problemas metodológicos a los que se enfrenta la sociolingüística que estudia cortes sincrónicos contemporáneos, se añaden ahora otros de considerable entidad. El investigador de la diacronía no solo tiene que lidiar con categorías sociales no siempre fáciles de delimitar, sino que, además, debe hacerlo para el estudio de etapas históricas en las que tales nociones pueden no ser homologables a las actuales (Burke 1992). Como han destacado diversos autores (Nevalainen 1996; Conde-Silvestre/Hernandez-Campoy 2004; Conde-Silvestre 2007; Bergs 2012), la sociolingüística histórica no debe incurrir, pues, en anacronismos y dar por asumidas a priori clasificaciones que hoy utilizamos con sentidos muy concretos. Para evitarlo, las categorías empleadas deben ser acordes con la estructura social 
de los periodos investigados, algo para lo que resulta indispensable acudir a las fuentes históricas, pero también al propio contenido de unos textos que, como las cartas privadas o las memorias y diarios utilizados aquí, aportan informaciones muy valiosas acerca de la sociedad y del tipo de relaciones que imperaron en cada época.

A continuación, repasamos los factores extralingüísticos examinados en el presente estudio, dando cuenta del modo en que se han configurado y las eventuales dificultades que hemos encontrado en cada caso.

\subsubsection{Sexo}

Como recuerda Nevalainen $(1999,510)$, la polémica acerca de la oportunidad de utilizar las nociones de sexo o género, que ha ocupado a los investigadores durante las últimas décadas, tiene probablemente menos sentido en el estudio de épocas pasadas, cuando el papel de la mujer era mucho más restringido que en la actualidad. Con todo, el análisis de este predictor, que se ha demostrado clave para explicar la variación y el cambio lingüístico en numerosas ocasiones, plantea a menudo problemas serios en la investigación sobre estadios de lengua pretéritos, fundamentalmente por razones metodológicas (Bergs 2012, 89; Kielkiewicz-Janowiak 2012, 307-309). A este respecto, la general escasez de muestras escritas a cargo de mujeres, especialmente en periodos remotos, supone un considerable problema de representatividad en las investigaciones de sociolingüística histórica. Nuestro estudio no es una excepción, dado que las ocurrencias del bloque femenino apenas sobrepasan el 11\% de los datos disponibles, aunque su distribución en los periodos estudiados es irregular. En este sentido, disponemos de muestras algo mejor representadas en los periodos clásico (14\%) y contemporáneo (13\%), siendo especialmente deficientes las del español moderno, donde apenas superan el 4\%. Ello dificulta, sin duda, el análisis de regresión, por lo que, en la mayoría de los casos habrá que tomar con cautela eventuales diferencias frecuenciales entre los resultados de uno y otro sexo. Aun así, puede ser interesante evaluar el sentido de esas potenciales diferencias, especialmente si estas se repiten de manera recurrente.

Se ha dicho que, en situaciones de variación estable, las formas vernáculas, como en este caso las soluciones queístas, son generalmente más esperables en el habla masculina que en la femenina (Labov 2001; Blas Arroyo 2005; Tagliamonte 2012; Queen 2013). Y lo contrario sucede con aquellas que la normativa impone como formas de prestigio, como las inserciones preposicionales. Sin embargo, estas presiones no han tenido por qué ser siempre idénticas, aunque se hayan agudizado en tiempos recientes, cuando gramáticas y demás obras precep- 
tivas han llamado repetidamente la atención acerca de los «vicios» que suponen fenómenos como el dequeísmo y-aunque en menor medida (ver supra §2.3)—el queísmo.

Por otro lado, es también un resultado habitual que, en las situaciones de cambio lingüístico hacia nuevas formas de prestigio, las mujeres suelen actuar también como un importante vector de difusión. Sin embargo, es más difícil determinar en qué fase del cambio comienzan a operar estas diferencias generolectales. Para Labov (2001), por ejemplo, esta especialización se produce ya desde época temprana. ${ }^{17}$ Sin embargo, en su estudio sobre algunos cambios gramaticales que afectaron al inglés durante las dinastías Tudor y Estuardo, Nevalainen/Raumolin-Brunberg $(2003,130)$ han concluido que el factor generolectal comienza a operar significativamente en la matriz social a partir del momento en que los cambios han superado las fases iniciales, situándose ya en proporciones más avanzadas de la curva en S (entre el 15\% y el 40\%). Además, señalan que las mujeres muestran «[...] advantage in language change regardless of the social embedding of the process» (para otros estudios que se han ocupado de este mismo factor en la sociolingüística histórica, véanse Palander-Collin 1999; Raumolin-Brunberg 2006; Nurmi/Nevala/Palander-Collin 2009; Blas Arroyo 2016, entre otros).

Hasta donde llega nuestro conocimiento, el factor generolectal no se ha estudiado en la historia del fenómeno que nos ocupa. Por el contrario, sí lo ha hecho en investigaciones basadas en corpus orales contemporáneos, aunque los resultados están lejos de ser unánimes. En aquellos que utilizan una metodología estadística más sofisticada, basada en los resultados de la regresión logística, las diferencias generolectales no han solido superar el umbral de significación. Entre las pocas excepciones figura el estudio de Almeida (2009a) sobre el corpus de Tenerife de 1996, en el que las mujeres (59\%) superan significativamente a los hombres (39\%) en las soluciones queístas. En un corpus anterior (compilado en 1980), el sociolingüista canario había advertido diferencias del mismo tenor, aunque esta vez sin el suficiente aval estadístico. Esto último sucede también en otros estudios, en los que las diferencias entre hombres y mujeres son menores, aunque puede ser revelador que, en la mayoría, estas últimas superan también a los primeros en el uso de las formas queístas. Así sucede en Santiago de Chile (San Martín 2016), Caracas (Bentivoglio/Galué 1998-1999), Valencia (Gómez Molina/ Gómez Devís 1995; Gómez Molina 2013), Sevilla (Carbonero 1991), Ciudad de México (nivel popular) (Arjona 1979) y Rosario (norma culta) (Boretti de Macchia

17 Labov (2001) advierte que, ya en la segunda etapa de los cambios, se produce esta diferenciación generolectal, de tal manera que las variantes novedosas aparecen asociadas bien a los hombres, bien a las mujeres, en función del prestigio que adquieren. 
1991). Con todo, y aunque en menor número, no faltan ejemplos en los que se observa la tendencia contraria: San Juan de Puerto Rico (tanto en la norma culta (Dietrick 1992) como en el nivel popular (Rivera Mercado 1998), Salta (Del Valle 1996-1997), Lima (norma culta) (McLauchlan 1982).

\subsubsection{Estatus social}

A partir inicialmente de una división tripartita que facilite las comparaciones, en la configuración de este predictor social atenderemos a la estructura social de cada etapa histórica, con el fin de eludir los anacronismos a los que nos referíamos más arriba. ${ }^{18}$ Así, en una sociedad rígidamente estamental como la España de los Siglos de Oro (Elliot 1998, Fernández Álvarez 2004), el estrato alto está representado por miembros de la monarquía, la aristocracia y el alto clero, investidos de un enorme poder político, económico y social. En este grupo, incluimos también a algunos representantes destacados de la élite cultural española del momento, como escritores, eruditos, humanistas, gramáticos, etc. cuya huella en la lengua clásica fue indeleble. Un segundo estamento, difícilmente homologable a las actuales clases medias, incluye una nómina variada de miembros del clero y la nobleza baja, cuya fortuna iría disminuyendo con el paso del tiempo, aunque con algunas excepciones. ${ }^{19}$ A estos se añaden los representantes de una creciente burguesía urbana, compuesta por bachilleres, licenciados, médicos, escribanos, abogados, mercaderes, maestros, etc. y demás profesiones «liberales», cuyas posibilidades de ascenso social no eran imposibles, pero sí considerablemente limitadas. Por último, en el nivel más bajo se sitúa el pueblo llano, representado por individuos que ejercen profesiones manuales, como campesinos, panaderos, carpinteros, torneros, toneleros, albañiles, herreros, y un largo etcétera, muchos de los cuales probaron fortuna en tierras americanas, desde las que escribían a sus familiares en España para dar noticias o pedir la anhelada reunificación familiar (Fernández Alcaide 2009; Stangl 2012). En este último grupo nos encontramos con textos cuya autoría

18 Algunos autores han propuesto evitar el concepto de clase en el estudio de etapas anteriores a la Revolución industrial, sustituyéndolo por otros más acordes con la jerarquía social de esos periodos, como rango social (social rank) u orden social (social order), entre otros (Nevalainen 1996; Conde-Silvestre/Hernandez-Campoy 2004). Para una discusión acerca de las ventajas e inconvenientes que plantean diversos modelos de este tipo en la Gran Bretaña anterior al siglo xIX, véanse Nevalainen/Raumolin-Brunberg (2003) y Conde-Silvestre/Hernández-Campoy (2005).

19 Este fue el caso de algunos conquistadores y aventureros, procedentes en muchos casos de la nobleza baja, que probaron fortuna en América, a veces, con notable éxito. 
parece indiscutible a la vista del nivel de lengua utilizado, pero que fueron trasladados al papel por intermediarios, que recogían por escrito lo que aquellos les dictaban. Pese a ello, algunos estudios han comprobado que la influencia que pudieron ejercer estos escribas fue menor, y no falsea la representatividad de los textos, al menos en los niveles gramatical y discursivo. ${ }^{20}$ Así, en su estudio sobre las cartas privadas que varios miembros de la familia Paston escribieron a caballo entre los siglos XV y XVI, Bergs (2005) comprobó que la morfosintaxis hallada en sus textos era significativamente distinta, y ello pese a haber sido trasladadas al papel por un mismo escribano (en el mismo sentido, véase también Pahta/Jucker 2011). Del mismo modo, en un estudio acerca de la variación entre las perífrasis modales deber y deber de + infinitivo en correspondencia privada de los siglos XVI y XVII, en otro lugar tuvimos ocasión de comprobar cómo los resultados obtenidos tras la comparación entre textos autógrafos y dictados eran singularmente parecidos, y no solo en términos frecuenciales, sino también en la dirección explicativa de los factores condicionantes (Blas Arroyo 2016).

La composición de los diferentes estratos sociales en etapas de la historia más avanzadas experimenta, sin embargo, algunos cambios destacados. Así, en el periodo moderno, que en el presente estudio extendemos desde comienzos del siglo XVIII al primer tercio del XIX (ver infra §3.3.6), la cúspide social sigue representada por la aristocracia y el alto clero, pero a ella se incorporan ya algunos miembros de los estratos intermedios (comerciantes, abogados, etc.), que hasta ese momento habían visto muy dificultado su ascenso social, pero cuya fortuna (en muchos casos, vinculada con el comercio transatlántico) favoreció su integración en la cúspide social de la época. Por último, estas tendencias de movilidad social se intensifican en el periodo contemporáneo, cuando los contactos y trasvases entre unos grupos y otros serán ya más fluidos. Con todo, incluso en esta época, las diferencias entre unos sociolectos y otros son bien visibles, tanto en la forma como en el fondo de los textos, y de ello encontramos numerosos ejemplos en el corpus. Así, en las cartas, escritas ya directamente por los representantes del estrato bajo, en un momento histórico en el que el acceso a la escritura había conocido un progreso significativo con respecto al pasado, los rasgos vernáculos son muy frecuentes, y afectan a prácticamente todos los niveles del análisis lingüístico. Los siguientes fragmentos, extraídos de una carta escrita en 1925 desde Argentina por José Naveiras a su hermano en Galicia, son un ejemplo representativo de esa vernacularización. En ellos se pueden observar numerosos errores en la puntuación, la acentuación (despues,

20 Otra cosa son los niveles fónico y gráfico, en los que la mano del escribano es determinante. 
mi, demas, etc.), las grafías (rrecivo, alles, saluz, ygualmente, etc.), la separación de palabas (denuestra parte), la sintaxis (a todos que por mi pregunten, de por parte al tio...), etc.:

(122) Querido Hermano despues de saludarte es mi deseo que al rrecivo de la presente te alles en perfecto estado de saluz ygualmente los demas quedando la nuestra buena por el momento sin nobedad [...] Estimado Hermano la presente es para darte contestación a tu rrecivida carta que se alla en mi poder desde el dia [...] Sin mas nobedades por el momento Recuerdos a los padrinos y a todos que por mi pregunten y de por parte al tio de casa y a nuestras hermanas y a Vicente y un abrazo y mil vesos a Juancito y vos los recibes de Eduardo y señora y demas familia y denuestra parte rrecibes el maior aprecio y cariño de este tu hermano

S.S.S. José Naveiras y Señora.

A diferencia de lo que sucede con el sexo, los estudios que han atendido a la potencial influencia de la estructura social en la suerte del queísmo en comunidades de habla contemporáneas han comprobado de manera casi sistemática un patrón de distribución lineal. ${ }^{21}$ En la cima de las realizaciones queístas se sitúan casi siempre los representantes de los niveles más bajos, seguidos por los estratos medios, y con las clases altas como principal freno a una mayor difusión social. Así se observa en Tenerife (Almeida 2009a), Santiago de Chile (San Martín 2016), Caracas (Bentivoglio/Galué 1998-1999; Guirado 2009), Salta (Del Valle 19961997), León (Cortés Rodríguez 1990) o en el portugués de Braga (Herdeiro/Barbosa 2015). Otros estudios señalan también la mayor frecuencia del queísmo en los niveles sociales bajos, aunque las diferencias entre los otros se neutralizan. Esto último ocurre en el estudio más reciente sobre el habla de Valencia (Gómez Molina 2013), aunque no así en un trabajo previo separado de este por un par de décadas (Gómez Molina/Gómez Devís 1995). En él, sus autores habían llamado la atención sobre un patrón distribucional curvilíneo, similar al detectado para el dequeísmo en diversas comunidades, y en el que el principal protagonismo en la difusión de las variantes vernáculas lo adquirían los estratos intermedios, quizá como reflejo de una mayor inseguridad lingüística entre sus miembros ante este hecho de variación sintáctica. Y lo mismo se ha advertido en el análisis del queísmo pronominal en Santa Cruz de Tenerife (Herrera Santana 1997). Por último, no han faltado tampoco otros resultados más esporádicos, en los que la dirección del efecto se invierte, de tal manera que son ahora los niveles altos quienes se sitúan en cabeza de las variantes elididas, como ha visto, por ejemplo, Boretti de Macchia (1989) en la ciudad de Rosario (Alto: 41\%; Medio: 30\%; Bajo: 27\%).

21 En algunos estudios, el parámetro utilizado para medir la variación sociolectal es únicamente el nivel de estudios, un factor que, en ocasiones, se ha propuesto como el más determinante para evaluar aquella (Moreno Fernández 1998; Blas Arroyo 2005). 


\subsubsection{Tenor}

Para la configuración de este predictor estilístico consideramos dos parámetros: la temática general de los textos y el tipo de relaciones que se establecen entre los participantes en el acto comunicativo. La combinación entre ambos ofrece diferentes tipos de textos, que se sitúan en posiciones también diferentes en un eje imaginario:

a) Cartas privadas intercambiadas entre miembros de la estructura familiar a los que unen estrechos lazos en el eje de la solidaridad (esposos, padres, hijos, hermanos, etc.). En el corpus, un número muy elevado de estas cartas corresponde a la correspondencia escrita por emigrantes en Indias, como las denominadas «cartas de llamada» (Otte 1987; Fernández Alcaide 2009; Stangl 2012), en las que un miembro de la familia que había marchado a América reclama a sus parientes más cercanos la reunificación familiar; o, en la dirección contraria, misivas redactadas por quienes habían quedado en España y escribían a sus familiares al otro lado del océano para contar detalles de sus vidas. Asimismo, se incluyen en este bloque otras cartas de contenido privado, que posteriormente serían utilizadas en pleitos judiciales (acusaciones de poligamia y otros delitos, etc.) por las personas que las recibieron (Martínez Martínez 2007).

b) Un segundo grupo de correspondencia responde a cartas, también de índole privada, y dirigidas a individuos situados en la misma posición en el eje del poder, pero en las que, a diferencia del bloque anterior, se tratan asuntos de carácter menos íntimo y personal. En este se incluyen, por ejemplo, las cartas de negocios entre socios y clientes, cuyo objeto principal es dar cuenta de temas económicos y comerciales. En parecido sentido cabe hablar de otro tipo de cartas en las que los participantes intercambian detalles acerca de la sociedad, las costumbres, la cultura, la moda, etc. de cada época. Finalmente, se incluye también aquí la correspondencia entre algunos miembros de la familia extendida (tíos-sobrinos, parientes lejanos, etc.), en las que el tono y la temática tratados es de naturaleza mucho menos íntima y solidaria que en el caso anterior, ya que en ella priman unos objetivos básicamente instrumentales (pedir ayuda económica, solicitar un favor, etc.).

c) El tercero grupo comprende la correspondencia entre individuos situados en diferentes puntos del eje del poder, y en la que se tratan asuntos no íntimos, ni personales. En este se incluyen tanto las misivas enviadas por las autoridades a sus subordinados, como las cartas remitidas en la dirección contraria, con las que estos últimos dan cuenta de sus actos a sus superiores. 
d) Un cuarto grupo de textos está formado por obras de carácter autobiográfico (diarios, memorias, etc.), en las que es frecuente la aparición del plano más personal de la comunicación, pero en las que, a diferencia de los textos del bloque (a) no hay un destinatario definido y, por tanto, falta el componente esencial de la dialogicidad.

e) Finalmente, el corpus se completa con algunas muestras más ocasionales de otros tipos textuales, como peticiones, denuncias, confesiones, declaraciones ante un tribunal, etc. en las que se advierte también una concepción oralizante, aunque despojada generalmente de una intencionalidad afectiva y carente también del elemento dialógico que preside las cartas.

Dadas las afinidades que se aprecian en el plano estilístico entre algunos de estos bloques, para facilitar el análisis de regresión, dividimos este factor en tres niveles, que denominamos cercano, intermedio y distante, respectivamente. Al primero corresponden las cartas del grupo (a). Por su parte, el nivel intermedio se nutre de las cartas menos personales del bloque (b) y de los textos autobiográficos del bloque (d). Finalmente, en el polo más distante de la comunicación, agrupamos tanto las cartas del grupo (c) como las tradiciones discursivas más esporádicas recogidas en (e).

Frente al sexo o la clase social, la variación estilística ha sido mucho menos considerada en la investigación sobre el queísmo en comunidades contemporáneas. Aun así, Schwenter (1999) advierte diferencias muy significativas entre el queísmo en textos orales (.73) y escritos (.38), de naturaleza más formal. Y, en el mismo sentido, Del Valle (1996-1997) observa distancias frecuenciales notables entre contextos informales (71\%) y formales (47\%) en la ciudad argentina de Salta.

\subsubsection{Contexto migratorio}

Aunque la inmensa mayoría de los textos incluidos en el corpus fueron escritos por autores nacidos en España, o residentes en este país durante buena parte de su existencia, las condiciones en que redactaron esos textos fueron muy distintas. Uno de los parámetros que más interés puede tener para nuestro objeto de estudio, y del que tenemos conocimiento en todos los casos, es el destino migratorio al que se vio abocado un ingente número de individuos que, por unas razones $u$ otras, aunque casi siempre en busca de un futuro mejor, probaron fortuna al otro lado del Atlántico. Aunque durante los primeros tiempos, estos movimientos masivos de población afectaron en menor medida a los territorios de la antigua Corona de Aragón, la presencia desde siempre de contingentes de muy diversa proceden- 
cia dialectal pudo ser un perfecto caldo de cultivo para soluciones lingüísticas derivadas de un intenso contacto interdialectal. Fenómenos de reestructuración, simplificación o koineización, entre otros, se han propuesto para explicar algunos fenómenos derivados de ese contacto (Fontanella de Weinberg 1992; Penny 2000; Tuten 2003; Granda 2004; Moreno Fernández 2005; Conde-Silvestre 2007; Kerswill 2013). En el presente estudio, deseamos también poner a prueba este factor mediante el análisis comparativo entre dos grupos de escritores. Por un lado, se encuentran aquellos que escribieron sus cartas y demás textos desde América, en contacto cotidiano con individuos de otras procedencias, $\mathrm{y}$, por consiguiente, en un entorno más favorable para la adopción de posibles soluciones simplificadoras, como las que, en este caso, representan las variantes queístas. Frente a estos se encuentran quienes escribieron desde España, en condiciones dialectales mucho más convencionales, y expuestas, por tanto, a una menor influencia interdialectal.

\subsubsection{Origen dialectal}

Incluso entre quienes no salieron de España, su procedencia pudo tener efectos sobre la variable lingüística. Aun así, la posibilidad de trabajar con este nuevo factor dialectal presenta algunas dificultades en el presente estudio. Por un lado, aunque el corpus ofrece muestras prácticamente de todas las regiones españolas, su distribución es irregular. Así, como hemos señalado ya, los datos correspondientes a las comunidades de habla orientales en los Siglos de Oro son reducidos, en paralelo al menor papel que estas desempeñaron en la conquista y población de América en los primeros momentos, aunque sus cifras mejoran ostensiblemente en los periodos siguientes. Por otro lado, y más relevante aún, no siempre disponemos de información suficiente para conocer la procedencia de los escritores. La consecuencia más relevante de esto último es que el predictor no puede incluirse junto a los demás en el análisis de regresión. Aun así, una comparación de las frecuencias con los materiales disponibles puede arrojar luz acerca de algunas tendencias de uso en ciertos dominios dialectales del español. Para ello, dividimos el predictor en dos grandes bloques, que se corresponden con algunas de las agrupaciones que más eco han tenido en el estudio diacrónico del español.

En el primer caso, distribuimos el lugar de procedencia de los escritores en comunidades de habla norteñas (desde Madrid hacia el norte peninsular) y centro-meridionales (las actuales comunidades autónomas de Castilla la Mancha, Extremadura, sur de la Comunidad Valenciana, Murcia, Andalucía y Canarias). Aunque la influencia de las comunidades septentrionales ha ocupado un papel relevante en la tradición filológica española, en los últimos tiempos autoras como Fernández Ordóñez (2011) han rebajado estas expectativas y han llamado la aten- 
ción acerca de la escasa difusión de algunos rasgos gramaticales y léxicos en el centro y sur peninsular, pese a que estos hunden sus raíces en el periodo medieval. De hecho, la «cuña» invertida del modelo pidaliano, que supuestamente habría llevado de norte a sur las innovaciones septentrionales, no siempre se ve confirmada por los hechos, viéndose sustituida por cambios originados desde otras latitudes.

Precisamente, la segunda clasificación a la que nos referíamos atiende a este último hecho. Así, especial interés tiene para nuestro objeto de estudio la relevancia que diversos autores han otorgado recientemente a las lenguas y variedades orientales en la evolución del español. Según esta hipótesis, ya desde el español medieval, el castellano fue muy permeable a la influencia lingüística de esas variedades, con consecuencias en diversos paradigmas, como la gramaticalización de los tiempos compuestos y el futuro, la aparición de algunas perífrasis, la consolidación de las formas compuestas de los pronombres personales, la generalización de la terminación -mente en los adverbios, entre otras (para un repaso de estos y otros desenlaces similares, véase Fernández Ordóñez 2011). Además, en la variable lingüística que nos ocupa en estas páginas, la sintaxis del español muestra diferencias estructurales destacadas con respecto a una lengua como el catalán, con la que mantiene un intenso contacto desde hace siglos. Así, en los casos de queísmo conjuntivo, mientras que en catalán el elemento regente y la subordinada van unidos sistemáticamente a través del nexo que, sin inserción preposicional alguna, en español las dos variantes han alternado a lo largo de la historia. A este respecto, véase el contraste entre los dos enunciados siguientes:

(123) Me convenció (de) que había estado enfermo.

(124) Em va convèncer $\emptyset$ que havia estat malalt.

Estas diferencias han llevado a algunos autores contemporáneos a postular la influencia de esta lengua en los usos queístas; una influencia que, de confirmarse, llevaría a usos queístas significativamente más frecuentes en estas áreas del este peninsular que en otras regiones (Seco 1989, Badia 1994; Gómez Torrego 1999).

\subsubsection{Factores temporales}

Por la general, se admite que las variantes queístas fueron la norma durante todo el periodo medieval, y que las inserciones preposicionales no alcanzaron cifras realmente significativas hasta la mitad del siglo XVII (Bentivoglio/Sedano 2011, 178), aunque algunos estudiosos adelantan este cambio a comienzos de esa misma centuria (Moreno de Alba 2009, §12.3.7.2) o, incluso, a las últimas décadas del 
XVI (Company Company/Bogard 1986, 246; Girón Alconchel 2004, 879; Herrero Ruiz de Loizaga 2005, 89; Guirado 2009, 25). Desde entonces se habría producido una evolución claramente favorable para estas construcciones prepositivas, hasta el punto de que, en opinión de Bogard/Company (1989, 271), «a partir del siglo XVIII no se documentan completivas de sustantivo sin preposición». Como contrapartida, en la sincronía actual, se estaría produciendo un retorno hacia el «esquema primitivo», ${ }^{22}$ que, aunque de manera residual, ${ }^{23}$ se mantuvo latente a lo largo de toda la historia del español (Bogard/Company 1989, 262-264; Leonetti 1999, 2089). Con todo, en este repaso histórico tan solo se contemplan algunas construcciones sintácticas aisladas, sin que haya referencias acerca del sino de otros tipos de variación contemplados en este trabajo.

Para valorar con más precisión el alcance de ese cambio lingüístico histórico, tanto en el fenómeno general como en cada una de las estructuras sintácticas analizadas, incluimos en el análisis diversos predictores temporales. Inicialmente, comprobaremos la incidencia de la variación en cada siglo (XVI, XVII, XVIII, XIX y XX). ${ }^{24}$ A continuación, para facilitar el análisis contrastivo, estos datos se condensarán en tres etapas más abarcadoras, coincidentes con tres periodos reconocidos habitualmente en la historia del español, y que, a efectos meramente expositivos, denominamos «clásico», «moderno» $y$ «contemporáneo». El primero comprende la lengua de los siglos XVI y XVII, ${ }^{25}$ el segundo abarca desde 1700 a 1835, mientras que el último periodo, en el que la lengua está ya prácticamente fijada, lo situamos en la horquilla temporal que va desde 1875 a 1960 . El examen de la variación en cada tipo de construcciones y en cada uno de estos periodos

22 Se trataría de un retorno a las soluciones queístas, de confirmarse los resultados de algunos estudios en tiempo real. Así, tras la comparación entre dos muestras de habla similares de la comunidad urbana de Tenerife entre los años 1980 y 1996, Almeida (2009a, 28) concluye que «los resultados del análisis del cambio en tiempo real muestran que se ha producido un incremento importante de los usos queístas en la comunidad». Y lo mismo parece derivarse del contraste entre los estudios de Gómez Molina/Gómez Devís (1995) y Gómez Molina (2013) sobre el español de Valencia, separados por casi veinte años.

23 Una opinión contraria es, sin embargo, la de Serradilla (1995, 147-148), para quien los usos queístas perduran significativamente hasta el siglo XX, por lo que el esquema queísta habría que calificarlo como «esencial» antes que «residual» en el español moderno. Como veremos, los resultados del presente estudio apuntan en esta misma dirección.

24 Más adelante, a estos se añade el presente estado de lengua, correspondiente a los primeros años del siglo XXI, cuyos datos analizaremos a partir de tres corpus orales representativos de otras tantas variedades del español peninsular actual (ver infra §8).

25 Como veremos, una excepción a esta regla es la representada por el análisis del queísmo en los complementos de categorías nominales, cuyos datos del XVI y del XVII se analizan por separado, dadas las diferencias considerables que se observan entre ambas centurias (para más detalles sobre esta cuestión, véase infra §5.2). 
nos permitirá comprobar no solo las fluctuaciones en los usos queístas, sino también-y sobre todo-por qué derroteros lingüísticos y extralingüísticos han circulado los cambios a lo largo de la historia.

Finalmente, en cada una de estas etapas añadiremos un predictor continuo para examinar con más detalle los potenciales cambios en su interior. De este modo, todos los ejemplos del corpus pasarán por el tamiz de la década en que fueron escritos.

\subsubsection{Informantes}

El análisis se completa con la inclusión de un predictor aleatorio, conformado a partir de la identidad de cada uno de los escritores. Como veremos (infra §4.2), la consideración de este tipo de predictores es fundamental para calibrar adecuadamente las tendencias de variación. Mediante su concurso-lo mismo que con las estructuras en la matriz lingüística (ver supra §3.2.1)—, los resultados son siempre más conservadores, pero, como contrapartida, mucho más fiables, pues permiten detectar posibles irregularidades en los datos, evitando así falsas interpretaciones.

La Tabla 4 resume a continuación los factores lingüísticos y extralingüísticos reseñados en este apartado. Con los signos más y menos se indica su inclusión o no en el estudio de cada una de las construcciones sintácticas.

Tabla 4: Síntesis de los factores considerados en el análisis por categorías.

\begin{tabular}{|c|c|c|c|c|c|}
\hline & $\begin{array}{l}\text { Complem. } \\
\text { adjetivos }\end{array}$ & $\begin{array}{l}\text { Complem. } \\
\text { sustantivo }\end{array}$ & $\begin{array}{l}\text { Complem. } \\
\text { verbos }\end{array}$ & Locuciones & Relativas \\
\hline Estructura & + & + & + & + & + \\
\hline Grado de fusión & + & + & - & - & - \\
\hline Modo subordinada & + & + & + & + & + \\
\hline Polaridad & + & + & + & + & + \\
\hline Priming 1 (Prep.) & + & + & + & + & + \\
\hline Priming 2 (que) & + & + & + & + & + \\
\hline Frecuencia & + & + & + & + & + \\
\hline Adyacencia & + & + & + & -26 & + \\
\hline Distancia & + & + & + & - & + \\
\hline
\end{tabular}

$26 \mathrm{El}$ factor no se considera en este bloque de construcciones, ya que tan solo contamos con dos ejemplos en los que la locución está separada del nexo que. 
Tabla 4 (continuación)

\begin{tabular}{|c|c|c|c|c|c|}
\hline & $\begin{array}{l}\text { Complem. } \\
\text { adjetivos }\end{array}$ & $\begin{array}{l}\text { Complem. } \\
\text { sustantivo }\end{array}$ & $\begin{array}{l}\text { Complem. } \\
\text { verbos }\end{array}$ & Locuciones & Relativas \\
\hline Preposición & + & + & + & - & - \\
\hline Persona & + & + & + & - & - \\
\hline Tiempo & - & - & + & - & - \\
\hline Relación paradigmática & + & + & + & - & - \\
\hline Determinación & - & + & - & - & + \\
\hline Función sintáctica & - & - & - & - & + \\
\hline Tipo de subordinada & - & - & - & - & + \\
\hline Posición & - & - & - & + & - \\
\hline Origen gramatical & - & - & - & + & - \\
\hline Sexo & + & + & + & + & + \\
\hline Estatus & + & + & + & + & + \\
\hline Tenor & + & + & + & + & + \\
\hline Contexto & + & + & + & + & + \\
\hline Origen (Norte/sur) & + & + & + & + & + \\
\hline Origen (Oriental/occid.) & + & + & + & + & + \\
\hline Siglo & + & + & + & + & + \\
\hline Periodo & + & + & + & + & + \\
\hline Década & + & + & + & + & + \\
\hline Informante & + & + & + & + & + \\
\hline
\end{tabular}


